\title{
Complement C5a impairs phagosomal maturation in the neutrophil through phosphoproteomic remodelling.
}

\section{Authors}

Alexander J.T. Wood ${ }^{1}$, Arlette M. Vassallo ${ }^{1}$, Marie-Hélène Ruchaud-Sparagano ${ }^{2}$, Jonathan Scott ${ }^{2}$, Carmelo Zinnato ${ }^{1}$, Carmen Gonzalez-Tejedo ${ }^{3}$, Kamal Kishore ${ }^{3}$, Clive S. D'Santos ${ }^{3}$, A. John Simpson $^{2,4}$, David K. Menon ${ }^{1}$, Charlotte Summers ${ }^{1}$, Edwin R. Chilvers ${ }^{1,5}$, Klaus Okkenhaug ${ }^{6}$, Andrew Conway Morris* ${ }^{1,6}$.

\section{Affiliations}

1 Department of Medicine, University of Cambridge, Addenbrooke's Hospital, Hills Road, Cambridge, CB2 0QQ UK.

${ }^{2}$ Faculty of Medical Sciences, Newcastle University, Framlington Place, Newcastle upon Tyne, NE2 $4 \mathrm{HH}, \mathrm{UK}$

${ }^{3}$ Cancer Research UK Cambridge Institute, University of Cambridge, Li Ka Shing Centre, Robinson Way, Cambridge, CB2 ORE UK.

${ }^{4}$ Newcastle upon Tyne Hospitals NHS Foundation Trust, Queen Victoria Road, Newcastle upon Tyne, NE1 4LP UK.

${ }^{5}$ National Heart and Lung Institute, Imperial College, Dovehouse Street, London, SW3 6LY, UK.

${ }^{6}$ Division of Immunology, Department of Pathology, University of Cambridge, Tennis Court Road, Cambridge, CB2 1QP, UK.

*Address for correspondence

Dr A Conway Morris,

Division of Anaesthesia, Department of Medicine

Level 4, Addenbrooke's Hospital

Hills Road

Cambridge UK

CB2 0QQ

ac926@cam.ac.uk 


\begin{abstract}
Critical illness is accompanied by the release of large amounts of the anaphylotoxin, C5a. C5a suppresses antimicrobial functions of neutrophils which is associated with adverse outcomes. The signalling pathways that mediate C5a-induced neutrophil dysfunction are incompletely understood. Healthy donor neutrophils exposed to purified C5a demonstrated a prolonged defect (7 hours) in phagocytosis of Staphylococcus aureus. Phosphoproteomic profiling of 2712 phosphoproteins identified persistent C5a signalling and selective impairment of phagosomal protein phosphorylation on exposure to $S$. aureus. Notable proteins included early endosomal marker ZFYVE16 and VATPase proton channel component ATPV1G1. A novel assay of phagosomal acidification demonstrated C5a-induced impairment of phagosomal acidification which was recapitulated in neutrophils from critically ill patients. Examination of the C5a-impaired protein phosphorylation indicated a role for the phosphatidylinositol 3-kinase VPS34 in phagosomal maturation. Inhibition of VPS34 impaired neutrophil phagosomal acidification and killing of $S$. aureus. This study provides a phosphoproteomic assessment of human neutrophil signalling in response to $S$. aureus and its disruption by $\mathrm{C} 5 \mathrm{a}$, identifying a defect in phagosomal maturation and new mechanisms of immune failure in critical illness.
\end{abstract}

Key words: Neutrophils, Complement system proteins, Staphylococcus aureus, Critical care, Phosphoproteome 


\section{Introduction}

2 Critically ill patients who require exogenous organ support as a result of severe physiologic insult, are

3 at high risk of secondary infections (Vincent et al, 2009). Critical illness may arise from a variety of

4 sterile or infectious insults. However, despite its varied aetiology, critical illness is often accompanied

5 by stereotyped immune dysregulation, with features of both hyperinflammation and immune-

6 mediated organ damage, as well as impairment of anti-microbial functions (Meakins et al, 1977;

7 Conway Morris et al, 2013; Hotchkiss et al, 2013a). Critical illness is estimated to cause 58 million

8 adult deaths per year globally, (Adhikari et al, 2010) and whilst much of the mortality is attributable

9 to the underlying condition, secondary infections make a significant contribution to the eventual

10 outcome (Adhikari et al, 2010; Scicluna et al, 2015; van Vught et al, 2016; Vincent et al, 2006).

12 Impairment of immune cell function predicts secondary infection, (Hotchkiss et al, 2013b; Conway

13 Morris et al, 2013; Demaret et al, 2015; Landelle et al, 2010) and failure of neutrophil phagocytosis

14 and bacterial killing has been demonstrated to be one of the strongest predictors of these infections. A

15 key driver of the functional impairment of neutrophils is the anaphylatoxin C5a (Conway Morris et al,

16 2009, 2011; Huber-Lang et al, 2002b). However, there remain no efficacious treatments for critical-

17 illness induced immune dysfunction, in part because the mechanisms that underpin C5a-induced

18 dysfunction are incompletely understood.

20 A wealth of data have demonstrated the importance of C5a in driving classical inflammatory events in 21 neutrophils, including chemotaxis (Ward \& Newman, 1969; Ehrengruber et al, 1994), generation of 22 reactive oxygen species (ROS) (Suire et al, 2006; Mazaki et al, 2006; Huber-Lang et al, 2002b), 23 phagocytosis (Mollnes et al, 2002; Brekke et al, 2007), degranulation (Denk et al, 2017a, 2017b), and 24 delayed apoptosis (Lee et al, 2008; Perianayagam et al, 2002, 2004). One of the key questions in this 25 area is how to explain the divergent findings of C5a being a critical co-factor in phagocytosis

26 (Mollnes et al, 2002; Brekke et al, 2007), but also capable of suppression of phagocytosis in sepsis 27 and critical illness (Conway Morris et al, 2009, 2011; Huber-Lang et al, 2002b). In critical illness, 28 dysregulated activation of the complement and coagulation cascades occurs, leading to exposure of 29 neutrophils to high concentrations of C5a (Hotchkiss et al, 2013a; Venet \& Monneret, 2018; Lord et 30 al, 2014; Conway-Morris et al, 2018; Ward, 2004). In these circumstances, we and others have shown 31 that C5a reduces neutrophil phagocytosis and ROS production in both rodent models and critically ill 32 patients (Conway Morris et al, 2009, 2011; Czermak et al, 1999; Huber-Lang et al, 2002b). Further, 33 C5a exposure has been shown to be associated with nosocomial infection, organ failure, and increased 34 mortality in critically ill patients (Conway Morris et al, 2011, 2009, 2013; Czermak et al, 1999;

35 Huber-Lang et al, 2001, 2002a). 
37 Whilst several signals mediating aspects of C5a-induced neutrophil dysfunction have been established

38 (Conway Morris et al, 2011; Denk et al, 2017a; Huber-Lang et al, 2002b), a global picture of

39 signalling in neutrophils encountering common pathogens and how this process is perturbed by C5a

40 does not exist. Such studies are challenging in neutrophils owing to their high degradative enzyme

41 content and short in-vitro survival times (Luerman et al, 2010).

42

43 This study aimed to characterise the neutrophil phosphoprotein response to a common nosocomial

44 pathogen, Staphylococcus aureus, and investigate how this is perturbed by prior exposure to C5a.

45 Our differential phosphoprotein analysis implicated C5a in altered phagosomal maturation, findings

46 that we confirmed with functional neutrophil assays in C5a-treated healthy donor cells and those from

47 critically ill patients. The phosphoprotein response to $S$. aureus implicated the involvement of the

48 phosphatidylinositol 3-kinase VPS34, hence we continued examined the effects of this enzyme on

49 phagosomal maturation. 


\section{Results}

\section{C5a induces a prolonged defect in neutrophil phagocytosis of bacteria}

52 C5a induces a defect in phagocytosis of the clinically relevant bacterial species $S$. aureus (Figure 1A)

53 and E. coli (1B). Pulse exposure of neutrophils to C5a revealed a persistent defect in phagocytosis

54 lasting at least seven hours (1C), with short pulses inducing a significant defect. These effects were

55 not explained by the loss of cell viability (1D). A similar prolonged defect was identified in the whole

56 blood assay (1E), representing continuous exposure of neutrophils to C5a (which cannot be washed

57 off in this assay). The ability of C5a to inhibit phagocytosis was dependent on the temporal

58 relationship between C5a and S. aureus exposure. Only pre-exposure to C5a induced the defect in

59 phagocytosis, whereas co-exposure or the addition of C5a 30 minutes after $S$. aureus addition failed to

60 induce a defect $(1 \mathrm{~F})$. In a dose titration we could not identify any dose which enhanced phagocytosis,

61 with progressive decrease in phagocytosis as concentration of C5a was increased (Figure S1A).

63 To explore the potential mechanisms whereby pre-exposure to $S$. aureus prevents the inhibitory effect

64 of C5a, we examined whether this could be due to reduced C5aR1 expression. Although we could

65 demonstrate a reduction in C5aR1 following S. aureus exposure (Figure S1B), this was modest and

66 similar to the reductions induced by other inflammatory mediators including lipopolysaccharide

67 (LPS) and leukotriene A (LTA), neither of which ameliorated the subsequent suppressive effect of

68 C5a (Figure S1C). Further, C5a and not LPS, LTA, granulocyte-macrophage colony-stimulating

69 factor (GM-CSF) and tumour necrosis factor (TNF) reduced neutrophil phagocytosis (Figure S1D).

70 To confirm the functional relevance of C5a-impaired phagocytosis, we demonstrated that C5a pre-

71 treatment reduced bacterial killing of S. aureus (Figure S1E).

73 Given the temporal dependence of the inhibitory effect of C5a, we examined whether prior exposure

74 to $S$. aureus enhanced or impaired subsequent ingestion. Using sequential exposure of whole blood to

75 S. aureus labelled with two different pHrodo probes, we demonstrated that neutrophils which ingest

76 the first target are more likely to ingest the second target (Figure S2A), whilst progressive increase in

77 the first target revealed a fundamental limit on the capacity of neutrophils to ingest (Figures S2B and 78 C).

\section{S. aureus and C5a induce widespread changes in the neutrophil phosphoproteome}

81 Although key signalling 'nodes' have been identified in neutrophils following C5a exposure (Conway

82 Morris et al, 2009, 2011), no map of global signalling networks has been produced. Given the

83 rapidity of the C5a-induced phagocytic impairment demonstrated above, and the known signalling 
84 kinetics of G-protein coupled receptors (GPCRs) (Lohse et al, 2008), we examined post-translational

85 modification by phosphorylation (i.e. a phosphoproteomic approach).

86

87 In total, 4859 proteins and 2712 phosphoproteins were identified in peripheral blood neutrophils

88 obtained from four healthy volunteers. C5a-induced suppression of phagocytosis in these donors was

89 confirmed (Figure S3A), and technical reproducibility was high (Figures S3B-E) with the magnitude

90 of phosphorylation changes within the previously reported range (Papachristou et al, 2018). Changes

91 in the human proteome were minimal (2\% of total proteome with S. aureus treatment) whereas

92 phosphoprotein expression varied markedly (31.6\% of total phosphoproteome with S. aureus

93 treatment, Table S1). Figure 2 shows the top 2.5\% most variable phosphoproteins with protein

94 identification, whereas the top $25 \%$ are shown in Figure S4 to demonstrate wider changes within the

95 phosphoproteome. The phosphoproteomic and proteomic datasets are publicly available in the PRIDE

96 database (data available to reviewers, will be made public on acceptance of manuscript).

97

\section{C5a exposure induces persistent alteration in phosphoproteins across several pathways.}

99 Figure 3A shows a volcano plot comparing neutrophils treated with C5a versus vehicle control. 119

100 proteins were significantly differentially phosphorylated at 1 hour, indicating persistent signalling,

101 consistent with the prolonged inhibition of phagocytosis seen in Figure 1. Notably, C5aR1 remained

102 highly phosphorylated (a modification key to its internalisation) (Braun et al, 2003) and this change

103 has been used to identify C5a-exposed, dysfunctional neutrophils (Conway Morris et al, 2009, 2011,

104 2013, 2018; Schmidt et al, 2015; Unnewehr et al, 2013). Pathway enrichment using Metascape (Zhou

105 et al, 2019) indicated involvement of pathways including membrane trafficking, regulated exocytosis

106 (degranulation), and phosphatidylinositol-3,4,5-trisphosphate (PIP3) signalling which persist one hour

107 after stimulation with C5a (Figure 3B). Given the finding of a temporal dependency of C5a exposure

108 on phagocytosis (Figure 1F), we examined how the phosphoproteomic alterations after C5a compared

109 to those after $S$. aureus. The pathways showing prolonged activation after C5a exposure overlap with

110 those induced by S. aureus (Figure S5A) and many of the proteins are common to both conditions

111 (Figure S5B).

112

113 S. aureus induces a marked alteration in the phosphoproteome which is significantly impacted

114 by C5a exposure

115 Exposure of neutrophils to S. aureus induced a marked alteration in the phosphoproteome (Figure

$1164 \mathrm{~A}$ ); 863 proteins (31\% of the phosphoproteome) significantly alter their phosphor-status. Pathway

117 enrichment indicated the involvement of multiple pathways, notably Rho-GTPase signalling,

118 endosomal transport, degranulation, and actin cytoskeleton organisation (Figure 4B, with extended

119 heatmap showing top 100 pathways shown in Figure S6). 
121 C5a exposure prior to $S$. aureus reduced the phosphoprotein response to the bacterium considerably

122 (Figure 4C). However, comparing C5a and control treated cells exposed to S. aureus, 19 proteins

123 were identified, suggesting selective pathway modulation (Figure 4D). When mapped to known

124 pathways using Metascape (Zhou et al, 2019) and manually annotated from the Uniprot database (The

125 Uniprot Consortium, 2019), a pattern of reduced phosphorylation of phagosomal maturation proteins

126 (Table 1) and pathways (Figure 4E) emerged. Notably, early endosomal marker ZFYVE16 and its

127 interactor TOM1 had impaired phosphorylation following C5a exposure, as did V-type ATPase

128 subunit G1 (which is critical for phagosomal acidification). ZFYVE16 requires phosphatidylinositol-

129 3-phosphate (PI3P) for recruitment to the phagosome (Sorkin \& Von Zastrow, 2009). Another

130 prominent PI3P-responsive protein noted was Ras-related protein 7a (RAB7A), although this protein

131 was not differentially phosphorylated between the C5a/S. aureus and vehicle control/S. aureus

132 conditions. Figure S7 shows individual donor data for these key proteins.

134 Our dataset suggests that C5a exposure that precedes pathogen encounter prevents effective signalling

135 through the phagosomal maturation pathways, and links intracellular signalling to the prolonged

136 functional impairment noted in this context. The other major cluster of differentially phosphorylated

137 proteins were nuclear and nuclear membrane proteins, many of which are involved in mitosis and

138 nuclear envelope integrity.

\section{C5a induces an impairment in phagosomal acidification, distinct from the impairment in}

\section{1 ingestion.}

142 The phosphoproteomic signature of altered phagosomal maturation following C5a exposure, and the

143 involvement of V-ATPase suggested that C5a had effects beyond impaired ingestion of bacteria. To

144 disentangle the effects of phagocytic ingestion and phagolysosomal acidification, S. aureus

145 bioparticles co-labelled with the $\mathrm{pH}$-insensitive dye AF488 and $\mathrm{pHrodo}^{\mathrm{TM}}$ red were used. Neutrophils

146 ingested particles, and then subsequently acidified the phagosome, a process which could be ablated

147 by the addition of the V-ATPase inhibitor bafilomycin (Bowman et al, 1988) (Figures 5A and B). C5a

148 pre-treatment increased the proportion of neutrophils that failed to ingest particles (Figure 5C) and

149 increased the population that ingested particles but failed to acidify the phagosome (Figure 5D).

150 Recent reports suggest that $\mathrm{C} 5 \mathrm{a}$ induces $\mathrm{Na}^{+} / \mathrm{H}^{+}$exchanger-1 (NHE-1)-mediated cytoplasmic

151 alkalinisation (Denk et al, 2017a). An NHE-1 inhibitor did not alter the C5a-mediated effect on

152 phagosomal acidification (Figure 5E), suggesting that the pathways mediating these two effects of

153 C5a on neutrophils are distinct. Furthermore, we confirmed previous work (Huber-Lang et al, 2002b)

154 showing C5a impaired ROS production (Figure S8), which in combination with the current findings, 
155 suggests C5a induces a generalised failure of phagosomal maturation in addition to its effect on

156 phagocytic ingestion.

\section{VPS34 inhibition impairs phagosomal acidification}

The differential phosphoprotein analysis (Table 1) and phagosomal acidification assays (Figure 5) demonstrated impaired phagosomal maturation after exposure to C5a. As noted, several of the phosphoproteins that were differentially phosphorylated are known interactors with PI3P. The phosphatidylinositol 3-kinase VPS34 is the dominant source of PI3P in mammalian cells (Devereaux et al, 2013). Although VPS34 itself was detected, its phosphorylation status was not significantly altered. However, the finding that C5a altered the phosphorylation status of PI3P-responsive proteins led us to explore the role of VPS34 in phagosomal acidification. We used the selective inhibitor, VPS34IN1 (Bago et al, 2014) to examine the role of this enzyme in phagosomal acidification, and how this related to the defect induced by C5a. VPS34IN1 did not alter the percentage of neutrophils that underwent phagocytosis (Figure 6A and time-course in E) but did lead to a reduction in the overall number of particles ingested (Figure 6B) and a more marked reduction in pHrodo signal (Figure 6C and time course in F), indicating VPS34IN1 impairs phagosomal acidification. VPS34 inhibition also led to an impairment in the killing of S. aureus (Figure 6D), similar to that observed with C5a (Figure S1D) without a significant reduction in phagosomal ROS production (Figure S9).

177 To establish the relevance of our findings to the clinical setting, we used our assay of phagosomal

178 acidification to interrogate neutrophils obtained from critically ill patients and healthy volunteers. We assessed neutrophil function in critically ill patients, defining neutrophil dysfunction as phagocytosis of $<50 \%$ in our previously established zymosan assay (Figure 7A), a threshold associated with a markedly increased risk of nosocomial infection (Pinder et al, 2018; Conway Morris et al, 2009, 2011). Using our phagosomal acidification assay, we then compared patients with dysfunctional neutrophils to critically ill patients with functional neutrophils and healthy controls. Dysfunctional neutrophils exhibited a failure of phagosomal acidification (Figure 7B) that was not seen in patients with functional neutrophils. Furthermore, we observed a correlation between C5aR1 expression (decreased after C5a exposure) and phagocytosis (Figure 7C) and an inverse correlation between

187 C5aR1 expression and phagosomal acidification (Figure 7D), though the latter correlation did not 188 reach statistical significance. The patients with dysfunctional and functional neutrophils could not be 189 readily identified by clinical factors such as severity of illness or precipitating insult (Table S2). These 
190 data provide evidence of dysfunctional phagosomal acidification in critically ill patients and imply a

191 role for C5a in driving this dysfunction.

192 Discussion

193 Our data demonstrate that C5a induces both a prolonged defect in phagocytosis of relevant pathogens

194 (S. aureus and E.coli), and persistent signalling across multiple pathways for some hours after the

195 well characterised initial signalling events such as ionised calcium flux (Blackwood et al, 1996) and

196 PIP3 generation (Houslay et al, 2016). This finding supports the proposal that persistent C5a-induced

197 signalling may mediate the neutrophil dysfunction observed in critically ill patients (Conway Morris

198 et al, 2009, 2011).

199

200 To our knowledge, the data presented here (Figures 3-5) represent the deepest sequencing of the

201 human neutrophil proteome and phosphoproteome (Muschter et al, 2015; Tak et al, 2017; McLeish et

$202 a l, 2013)$. These data provide a phosphoproteomic assessment of the human neutrophil response to $S$.

203 aureus and C5a. Unlike transcriptomic data (Juss et al, 2016; Rorvig et al, 2013; Kobayashi et al,

204 2002), phosphoproteomics provides a direct assessment of mediators that are likely to have functional

205 implications, especially in short-lived cells such as neutrophils (Luerman et al, 2010; Fessler et al,

206 2002) and early pathogen exposure timepoints, as examined in this study.

207

208 The marked changes observed in phosphoproteins in response to S. aureus are perhaps unsurprising,

209 as the response to and clearance of bacteria are primary functions of neutrophils. Many of the

210 pathways identified (Figures 4 and S4) are consistent with established literature on neutrophil

211 responses to $S$. aureus, and indeed other bacteria, including activation of PI3K (Li et al, 2016), toll-

212 like receptor signalling (Jann et al, 2011) and neutrophil degranulation (McGovern et al, 2011).

214 The enrichment of PI3K and Rho GTPase signalling on C5a stimulation are in keeping with our

215 previous identification of key roles for these molecules in C5a-mediated functional deficits in

216 neutrophils (Conway Morris et al, 2009, 2011; Scott et al, 2015). The marked suppression of the

217 phosphorylation response to S.aureus induced by C5a pre-treatment is not simply a response to

218 reduced particle ingestion. Fifteen minutes after pathogen contact there were limited differences in the

219 ingestion rates between C5a and control treatments, and these became more marked over time (Figure

220 1). Furthermore, the differential analysis of $\mathrm{C} 5 \mathrm{a} / S$. aureus versus vehicle control/S. aureus conditions

221 identified defects in specific signalling pathways, most notably those involving endosomal trafficking.

222 This led us to examine the process of phagosomal maturation, and to identification of a C5a-induced

223 failure of phagosomal acidification (Figure 5) with similar findings in critically ill patients (Figure 7).

224 Failure of phagosomal maturation and intracellular killing has been described in primary immune 
deficiency (Buvelot et al, 2017), but has not previously been described as part of the immuno-paresis of critical illness. Impaired phosphorylation in pathways involving nuclear envelope breakdown and nuclear pore disassembly by C5a was unanticipated. The functional relevance of these changes remains unclear, though they may be early processes in the formation of non-lethal DNA-containing neutrophil extracellular traps (NETs) (Pilsczek et al, 2010).

Important signalling proteins involved in the process of phagosomal maturation (such as RAB7A, TOM1 and ZFYVE16) can be recruited to the phagosomal membrane by PI3P produced predominantly by VPS34 (Botelho et al, 2000; Levin et al, 2016; Sorkin \& Von Zastrow, 2009). Both ZFYVE16 and TOM1 phosphorylation were impaired by C5a exposure. We investigated the role of VPS34 as a mediator of neutrophil bactericidal function, and found that selective VPS34 inhibition produced a similar impairment in phagosomal acidification to that observed with C5a (Figure 6). The finding that a similar defect could be induced by inhibiting VPS34, the dominant source of PI3P in neutrophils (Devereaux et al, 2013), adds further validation to the pathway signature identified in the phosphoproteomic profile.

Ellson and colleagues (Ellson et al, 2001) demonstrated that PI3P plays an important role in targeting neutrophil oxidase components to phagosomal membranes and its importance in phagosomal maturation has also been identified in Dictyostelium discoideum (Buckley et al, 2019), murine macrophages, and macrophage-like cell lines (Naufer et al, 2018). However, the role of VPS34 in human neutrophils has previously been inferred indirectly (Anderson et al, 2008), owing to prior lack of selective inhibitors and the difficulties of genetically manipulating human neutrophils. Anderson and colleagues (Anderson et al, 2008) demonstrated a role for VPS34 in NADPH oxidase-mediated reactive oxygen species generation in neutrophils. We found a non-significant reduction in ROS production (Figure S9) that was much less marked than the effect on phagosomal acidification. The reasons for these divergent findings are uncertain, though may include differences in ROS measurement assays, our use of a selective VPS34 inhibitor, and differences between primary human neutrophils and cell lines. The mechanism by which VPS34 inhibition impairs killing of $S$. aureus requires further investigation, as phagosomal acidification is not thought to be critical to this process (Lacoma et al, 2017) and it is likely that the enzyme inhibition leads to further defects in phagosomal maturation. It is intriguing to note that whilst VPS34 inhibition does not reduce the percentage of cells that undergo phagocytosis (Figure 6A), consistent with previous work (Anderson et al, 2008), it does reduce the number of particles ingested (Figure 6B). This is consistent with the finding that ingestion of an initial target facilitates ingestion of a subsequent target (Figure S2), implying a capacitive stage of phagocytosis. That VPS34 inhibition impairs this capacitive phase suggests a hitherto undescribed relationship between phagosomal maturation and the capacity of cells to ingest particles. 
262 Our data also demonstrate that the timing of C5a exposure (before, alongside, or after pathogen

263 encounter) has an important effect on neutrophil function. Only pre-exposure to C5a impaired

264 subsequent neutrophil phagocytosis (Figure 2). Reduced C5aR1 availability for ligation by C5a is

265 unlikely to explain this observation, as C5aR1 downregulation is induced by multiple agents that do

266 not have the same effect on phagocytosis (Figure S1D). The pathways enriched under C5a conditions

267 are also represented amongst those enriched for following $S$. aureus exposure, with all but 8 of the

268 C5a-induced significantly altered phosphoproteins also being identified following S. aureus. It is

269 therefore plausible that signalling induced by S. aureus overwhelms C5a-induced phosphorylation

270 events unless they were established prior to $S$. aureus exposure. Indeed, the signalling induced by

271 initial ingestion may facilitate subsequent ingestion, as identified in the sequential exposure assay

272 (Figure S2), actively mitigating against C5a-induced suppression. We did not identify a dose at

273 which C5a enhanced phagocytosis in this work (Figure S1A) or indeed in our previous work (Conway

274 Morris et al, 2009, 2011). Collectively, these findings imply that the divergent findings on the effect

275 of C5a on phagocytosis when C5a is added exogenously, as in this report or generated by direct

276 addition of bacteria to blood as reported by Mollnes and colleagues (Mollnes et al, 2002; Brekke et al,

277 2007), are due to the temporal relationship between exposures rather than a biphasic dose-response

278 relationship.

279

280 This finding of distinct temporal responses to C5a suggests that where neutrophils encounter bacteria

281 and C5a at the same time, such as at the site of infection, the phagocytic response is not impaired.

282 When complement activation spills over systemically and C5a exposure precedes neutrophil-bacterial

283 interactions - as occurs with systematic inflammation in critical illness and sepsis - dysfunction

284 occurs, impairing the host's ability to respond to invasive infections or subsequent bacterial insults

285 (Conway Morris 2013, 2018).

286

287 This study was conducted entirely in primary human neutrophils, using C5a, an established, clinically

288 relevant modulator of neutrophil function that has been linked to a range of adverse outcomes in

289 critically ill patients. The use of clinically relevant pathogens, and the development of a whole-blood

290 bacteraemia model, increases the relevance of our study to the in-vivo situation. Impaired ingestion of

291 zymosan by patient neutrophils has been associated with adverse outcomes including development of

292 subsequent nosocomial infection (Conway Morris et al, 2011). The finding that patients with such

293 impairment also manifest impaired phagosomal acidification that correlates with markers of C5a

294 exposure (Figure 7) suggests that the identified mechanisms may be clinically relevant.

296 Several potential limitations should be highlighted. The phosphoproteomic response to S. aureus was

297 evoked with heat-killed bacterial particles, conjugated with fluorescent dyes, and these may not fully

298 reflect the response to live bacteria, although they do allow parallel functional assessment and 
299 standardisation of the stimulus between donors and across research sites. Although whole blood is a

300 more physiologically relevant than cell-culture media, it remains an abstraction from the situation in-

301 vivo, as it must be anticoagulated and does not involve normal flow or interaction with a vascular

302 endothelium. Furthermore, the model may not reflect the function of neutrophils that have migrated

303 into tissues, where most bacterial infections occur. Technical limitations currently prevent efficient

304 phosphoproteomic assessment of cells from whole blood, and therefore isolated cells with the inherent

305 in-vitro artefacts must be used.

306

307 In conclusion, we have demonstrated the role of $\mathrm{C} 5 \mathrm{a}$ in mediating neutrophil dysfunction in the

308 clinically relevant setting of $S$. aureus and E. coli bacteraemia, and demonstrated that the effects of

309 C5a can persist for many hours and which is dependent on the temporal sequence of C5a and bacterial

310 exposure. We also describe the neutrophil phosphoproteomic response to S. aureus, and to prolonged

311 exposure to C5a. This approach identified a defective phagosomal maturation signature induced by

312 C5a, likely involving modulation of Class III PI3K-dependent pathways. Further, we have shown the

313 functional manifestation of this phosphorylation signature in a model of bacteraemia. Finally, the

314 clinical relevance of this failure of phagosomal acidification was observed in critically ill patients. A

315 deeper understanding of the biology of neutrophil dysfunction in critical illness is key to developing

316 effective treatments for a phenomenon associated with multiple adverse clinical outcomes. 


\section{Materials and methods}

\section{Donors}

Ethical permission for obtaining peripheral venous blood from healthy volunteers was provided by the Cambridge Local Research Ethics Committee (REC reference 06/Q0108/281) and all donors provided written, informed consent. Critically ill patient blood samples were obtained under an approval granted by the North East-Newcastle \& North Tyneside 2 Research Ethics Committee (REC reference: 18/NE/0036). Inclusion and exclusion criteria are detailed in the supplemental methods. Assent was provided by a personal or nominated consultee.

Further details of methods and reagents described below are available in the supplementary materials.

\section{Neutrophil isolation}

Neutrophils were isolated from citrated peripheral venous blood by using a modification of the discontinuous plasma-Percoll density gradient centrifugation technique initially described by Böyum in 1968.(Boyum, 1968)

\section{Phagocytosis of pHrodo ${ }^{\mathrm{TM}} \mathrm{S}$. aureus and E. coli Bioparticles by purified neutrophils}

Purified human neutrophils, suspended in Iscoves Modified Dulbecco's Medium (IMDM) with $1 \%$ autologous serum at a concentration of $5 \times 10^{6} / \mathrm{mL}$, were incubated in microcentrifuge tubes with purified human C5a or vehicle control. pHrodo-conjugated S. aureus or E. coli bioparticles were opsonised, in $50 \%$ autologous serum for 30 min prior to be being added to the suspended cells. Analysis was by flow cytometry (Attune NxT, Thermofisher)

\section{No-wash, no-lyse whole blood assay of neutrophil phagocytosis and ROS production}

Blood, collected into argatroban $150 \mu \mathrm{g} / \mathrm{mL}$, was treated with inhibitors or priming agents as indicated in the respective figure legends, before being exposed to $S$. aureus $\mathrm{pHrodo}^{\mathrm{TM}} /$ dihydrorhodamine (DHR) or E.coli $\mathrm{pHrodo}^{\mathrm{TM}}$. Aliquots were stained on ice with antiCD16 antibody, diluted and analysed by flow cytometry (Attune NxT).

In variations on this assay, $S$. aureus particles labelled with the $\mathrm{pH}$-insensitive dye AlexaFluor (AF)488 or dual labelled with AF488 and pHrodo red were used. pHrodo red conjugation of AF488 $S$. aureus was performed in-house using the pHrodo particle labelling kit (Thermofisher). Fluorescence of extracellular particles was quenched with trypan blue $(0.1 \mathrm{mg} / \mathrm{mlL})$. 
Patient samples were analysed in a different laboratory that did not have access to an Attune Nxt flow cytometer, to fit with established workflows in this laboratory red cells were lysed using Pharmlyse (BD Bioscience, Wokingham, UK) followed by washing twice using a Facswash Assistant (BD Bioscience) prior to undertaking flow cytometry (Fortessa, BD Bioscience).

\section{Bacterial killing assay - whole blood}

Methicillin-sensitive S. aureus (MSSA) bacteria (strain ASASM6, kind gift from Prof Gordon Dougan, University of Cambridge) were grown to early log-phase. Blood was collected into argatroban and incubated with bacteria for 1 hour. Human cells were lysed by addition of $\mathrm{pH} 11$ distilled water for 3 minutes before plating of serial dilutions on Colombia blood agar.

\section{Preparation of whole human neutrophil lysates for phosphoproteomics}

Neutrophils were isolated from whole blood as detailed above, and resuspended in RPMI 1640 media containing $10 \mathrm{mM}$ HEPES with $1 \%$ autologous serum (AS) at a concentration of $1 \times 10^{7}$ cells $/ \mathrm{mL}$.

\section{Proteomic and phosphoproteomic studies}

Triplicates of $1 \times 10^{7}$ neutrophils were treated with vehicle control or C5a (100 nM, 60 minutes) at 37 ${ }^{\circ} \mathrm{C}$ before addition of pHrodo ${ }^{\mathrm{TM}}$ S. aureus $(15 \mu \mathrm{g} / \mathrm{mL})$. Phagocytosis was allowed to occur for 15 minutes. Aliquots were withdrawn from each triplicate and pooled at the indicated timepoints. Cells were centrifuged at $400 \mathrm{~g}$ for $5 \mathrm{~min}$ at $4{ }^{\circ} \mathrm{C}$, supernatants aspirated, and cell pellets snap frozen in liquid nitrogen. Cells were lysed by the addition of $0.5 \%$ sodium dodecyl sulphate (SDS)/0.1 M triethylammonium bicarbonate (TEAB) buffer and sonication, before undergoing centrifugation, trypsin digestion, tandem mass tag labelling, fractionation, phosphopeptide enrichment, and liquid chromatography and tandem mass spectrometry (LC-MS/MS) analysis. The experimental schematic can be seen in Supplemental Figure S10.

\section{Statistical analysis of wet laboratory data}

Data are presented as individual data points with summary statistics (median and interquartile range (IQR) or mean and standard deviation (SD) according to whether data are normally distributed. Parametric or non-parametric statistical tests were applied as appropriate after data were tested for normality using the D'Agostino-Pearson test. Tests used for comparisons are indicated in figure legends. Two-tailed $P$ values were computed, $P<0.05$ was considered statistically significant. Nonsignificant differences have not been indicated in figures for clarity. Statistical analyses were undertaken using GraphPad Prism v8.0 (GraphPad Software; San Diego; California). 


\section{Statistical analysis of phosphoproteomics data}

Spectral .raw files from data dependent acquisition were processed with the SequestHT search engine on Thermo Scientific Proteome DiscovererTM 2.1 software. Data were searched against both human and $S$. aureus UniProt reviewed databases at a $1 \%$ spectrum level false discovery rate (FDR) criteria using Percolator (University of Washington). MS1 mass tolerance was constrained to $20 \mathrm{ppm}$, and the fragment ion mass tolerance was set to 0.5 Da. TMT tags on lysine residues and peptide $\mathrm{N}$ termini (+229.163 Da) and methylthio (+45.988 Da) of cysteine residues (+45.021 Da) were set as static modifications, while oxidation of methionine residues $(+15.995 \mathrm{Da})$ and deamidation $(+0.984 \mathrm{Da})$ of asparagine and glutamine residues were set as variable modifications. For TMT-based reporter ion quantitation, we extracted the signal-to-noise (S:N) ratio for each TMT channel. Parsimony principle was applied for protein grouping.

Peptide and phosphopeptide intensities were normalised across conditions using median scaling and then summed to generate protein and phosphoprotein intensities. Proteins and phosphoproteins were independently identified and quantified in all samples from all four donors; species not meeting these criteria were excluded from subsequent analysis. Log base 2 fold change ( $\log 2 \mathrm{FC})$ was calculated between conditions of interest, compared across $n=4$ donors and tested for statistical significance by limma-based linear models with Bonferroni's correction for multiple testing. Hierarchical clustering using Euclidean distance was undertaken on the entire dataset. Heatmaps and volcano plots were generated as shown in Results. Statistical analyses were performed in RStudio (RStudio Team, 2016) using the qPLEXanalyzer (Papachristou et al, 2018) package, and plots were produced using the ggplot2 (Wickham, 2016) package.

\section{Data sharing statement}

The mass spectrometry proteomics data have been deposited to the ProteomeXchange Consortium via the PRIDE (Perez-Riverol Y et al, 2019) partner repository with the dataset identifier PXD017092 and will be made public on acceptance after peer-review 


\section{Acknowledgements}

We gratefully acknowledge the generous gift of live methicillin sensitive $S$. aureus from Prof Gordon Dougan, University of Cambridge. This research was supported by the Cambridge NIHR BRC Cell Phenotyping Hub and the Cambridge NIHR Biomedical Research Centre. In particular we wish to thank Esther Perez and Natalia Savinykh for their advice on flow cytometry.

The views in this manuscript represent the views of the authors alone, and not those of the National Institute for Health Research or the Department of Health and Social Care.

\section{Authorship contributions (CRediT):}

AJTW: Conceptualisation, formal analysis, investigation, methodology, validation, visualisation, writing - original draft, review and editing.

AV: Investigation, methodology, writing - review and editing.

MHRS: Investigation, methodology, writing - review and editing.

JS: Investigation, methodology, writing - review and editing.

CZ: Investigation, writing - review and editing.

CGT: Investigation, methodology, writing - review and editing.

KK: Methodology, data curation, software, formal analysis, writing - review and editing.

CSDS: Project administration, resources, supervision, writing - review and editing.

AJS: Project administration, resources, supervision, writing - review and editing.

DKM: Project administration, resources, supervision, writing - review and editing.

CS: Methodology, validation, project administration, resources, supervision, writing - review and editing.

ERC: Conceptualisation, formal analysis, funding acquisition, methodology, project administration, resources, supervision, writing - review and editing.

KO: Project administration, resources, supervision, writing - review and editing.

ACM: Conceptualisation, formal analysis, funding acquisition, investigation, methodology, project administration, resources, supervision, validation, writing - original draft, review and editing.

\section{Funding and conflict of interest disclosures}

AJTW was a Gates Cambridge Scholar supported by the Gates Cambridge Trust from 2015-2018. ACM is supported by a Clinical Research Career Development Fellowship from the Wellcome Trust (WT 2055214/Z/16/Z). Grants to ACM from the Academy of Medical Sciences and European Society for Intensive Care Medicine supported this work. The NIHR Newcastle Biomedical Research Centre and by the MRC SHIELD Antimicrobial Resistance Consortium supported the acquisition of patient data included in the manuscript.

The work in ERC's laboratory is funded by the Medical Research Council, Wellcome Trust, NIHR Imperial Biomedical Research Centre and non-commercial grants from GlaxoSmithKline.

The work in CS's laboratory is funded by the Medical Research Council, the Wellcome Trust, The British Heart Foundation, the Cambridge NIHR Biomedical Research Centre, and non-commercial grants from GlaxoSmithKline, MedImmune and BristolMyersSquibb.

Competing interests: Nil 


\section{References}

Adhikari NK, Fowler RA, Bhagwanjee S \& Rubenfeld GD (2010) Critical care and the global burden of critical illness in adults. Lancet 376: $1339-1346$

Anderson KE, Boyle KB, Davidson K, Chessa TAM, Kulkarni S, Jarvis GE, Sindrilaru A, Scharffetter-Kochanek K, Rausch O, Stephens LR \& Hawkins PT (2008) CD18-dependent activation of the neutrophil NADPH oxidase during phagocytosis of Escherichia coli or Staphylococcus aureus is regulated by class III but not class I or II PI3Ks. Blood 112: 52025211

Bago R, Malik N, Munson MJ, Prescott AR, Davies P, Sommer E, Shpiro N, Ward R, Cross D, Ganley IG \& Alessi DR (2014) Characterization of VPS34-IN1, a selective inhibitor of Vps34, reveals that the phosphatidylinositol 3-phosphate-binding SGK3 protein kinase is a downstream target of class III phosphoinositide 3-kinase. Biochem. J. 463: 413-427

Blackwood RA, Hartiala KT, Kwoh EE, Transue AT \& Brower RC (1996) Unidirectional heterologous receptor desensitization between both the fMLP and C5a receptor and the IL-8 receptor. J. Leukoc. Biol. 60: 88-93

Botelho RJ, Teruel M, Dierckman R, Anderson R, Wells A, York JD, Meyer T \& Grinstein S (2000) Localized biphasic changes in phosphatidylinositol-4,5-bisphosphate at sites of phagocytosis. $J$. Cell Biol. 151: 1353-68

Bowman EJ, Siebers A \& Altendorf K (1988) Bafilomycins; A class of inhibitors of membrane ATPases from microorganisms, animal cells, and plant cells. Proc. Natl. Acad. Sci. 85: 79727976

Boyum A (1968) Isolation of mononuclear cells and granulocytes from human blood. Isolation of monuclear cells by one centrifugation, and of granulocytes by combining centrifugation and sedimentation at 1 g. Scand. J. Clin. Lab. Invest. Suppl. 97: 77-89

Braun L, Christophe T \& Boulay F (2003) Phosphorylation of key serine residues is required for internalization of the complement 5a (C5a) anaphylatoxin receptor via a $\beta$-arrestin, dynamin, and clathrin-dependent pathway. J. Biol. Chem. 278: 4277-4285

Brekke O-L, Christiansen D, Fure H, Fung M \& Mollnes TE (2007) The role of complement C3 opsonization, C5a receptor, and CD14 in E. coli-induced up-regulation of granulocyte and monocyte CD11b/CD18 (CR3), phagocytosis, and oxidative burst in human whole blood. $J$. Leukoc. Biol. 81: 1404-1413

Buckley CM, Heath VL, Guého A, Bosmani C, Knobloch P, Sikakana P, Personnic N, Dove SK, Michell RH, Meier R, Hilbi H, Soldati T, Insall RH \& King JS (2019) PIKfyve/Fab1 is required for efficient V-ATPase and hydrolase delivery to phagosomes, phagosomal killing, and restriction of Legionella infection. PLoS Pathog. 15: 1-26

Buvelot H, Posfay-Barbe KM, Linder P, Schrenzel J \& Krause KH (2017) Staphylococcus aureus, phagocyte NADPH oxidase and chronic granulomatous disease. FEMS Microbiol. Rev. 41: 139157

Conway-Morris A, Wilson J \& Shankar-Hari M (2018) Immune Activation in Sepsis. Crit. Care Clin. 34: $29-42$

Conway Morris A, Anderson N, Brittan M, Wilkinson TS, Mcauley DF, Antonelli J, Mcculloch C, Barr LC, Dhaliwal K, Jones RO, Haslett C, Hay AW, Swann DG, Laurenson IF, Davidson DJ, Rossi AG, Walsh TS \& Simpson AJ (2013) Combined dysfunctions of immune cells predict nosocomial infection in critically ill patients. Br. J. Anaesth. 111: 778-787

Conway Morris A, Brittan M, Wilkinson TS, McAuley DF, Antonelli J, McCulloch C, Barr LC, McDonald N a., Dhaliwal K, Jones RO, Mackellar A, Haslett C, Hay AW, Swann DG, Anderson N, Laurenson IF, Davidson DJ, Rossi AG, Walsh TS \& Simpson AJ (2011) C5amediated neutrophil dysfunction is RhoA-dependent and predicts infection in critically ill patients. Blood 117: 5178-5188

Conway Morris A, Datta D, Hari MS, Stephen J, Weir CJ, Rennie J, Antonelli J, Bateman A, Warner N, Judge K, Keenan J, Wang A, Burpee T, Brown KA, Lewis SM, Mare T, Roy AI, Hulme G, Dimmick I, Rossi AG, et al (2018) Cell $\square$ surface signatures of immune dysfunction risk $\square$ stratify critically ill patients: INFECT study. Intensive Care Med. 44: 627-635 
Conway Morris A, Kefala K, Wilkinson TS, Dhaliwal K, Farrell L, Walsh T, Mackenzie SJ, Reid H, Davidson DJ, Haslett C, Rossi AG, Sallenave JM \& Simpson AJ (2009) C5a mediates peripheral blood neutrophil dysfunction in critically ill patients. Am. J. Respir. Crit. Care Med. 180: 19-28

Czermak BJ, Sarma V, Pierson CL, Warner RL, Huber-Lang M, Bless NM, Schmal H, Friedl HP \& Ward PA (1999) Protective effects of C5a blockade in sepsis. Nat. Med. 5: 788-92

Demaret J, Venet F, Friggeri A, Cazalis M -a., Plassais J, Jallades L, Malcus C, Poitevin-Later F, Textoris J, Lepape A \& Monneret G (2015) Marked alterations of neutrophil functions during sepsis-induced immunosuppression. J. Leukoc. Biol. 98: 1-10 Available at:

Denk S, Neher MD, Messerer DAC, Wiegner R, Nilsson B, Rittirsch D, Nilsson-Ekdahl K, Weckbach S, Ignatius A, Kalbitz M, Gebhard F, Weiss ME, Vogt J, Radermacher P, Köhl J, Lambris JD \& Huber-Lang MS (2017a) Complement C5a Functions as a Master Switch for the $\mathrm{pH}$ Balance in Neutrophils Exerting Fundamental Immunometabolic Effects. J. Immunol. 198: 4846-54

Denk S, Taylor RP, Wiegner R, Cook EM, Lindorfer MA, Pfeiffer K, Paschke S, Eiseler T, Weiss M, Barth E, Lambris JD, Kalbitz M, Martin T, Barth H, Messerer DAC, Gebhard F \& Huber-Lang MS (2017b) Complement C5a-Induced Changes in Neutrophil Morphology During Inflammation. Scand. J. Immunol. 86: 143-155

Devereaux K, Dall'Armi C, Alcazar-Roman A, Ogasawara Y, Zhou X, Wang F, Yamamoto A, de Camilli P \& Di Paolo G (2013) Regulation of Mammalian Autophagy by Class II and III PI 3Kinases through PI3P Synthesis. PLoS One 8: 10-12

Ehrengruber M, Geiser T \& Deranleau D (1994) Activation of human neutrophils by C3a and C5A Comparison of the effects on shape changes, chemotaxis, secretion, and respiratory burst. FEBS Lett. 346: 181-184

Ellson CD, Gobert-Gosse S, Anderson KE, Davidson K, Erdjument-Bromage H, Tempst P, Thuring JW, Cooper M a, Lim ZY, Holmes a B, Gaffney PR, Coadwell J, Chilvers ER, Hawkins PT \& Stephens LR (2001) PtdIns(3)P regulates the neutrophil oxidase complex by binding to the PX domain of p40(phox). Nat. Cell Biol. 3: 679-682

Fessler MB, Malcolm KC, Duncan MW \& Scott Worthen G (2002) A genomic and proteomic analysis of activation of the human neutrophil by lipopolysaccharide and its mediation by $\mathrm{p} 38$ mitogen-activated protein kinase. J. Biol. Chem. 277: 31291-31302

Hotchkiss RS, Monneret G \& Payen D (2013a) Sepsis-induced immunosuppression: from cellular dysfunctions to immunotherapy. Nat. Rev. Immunol. 13: 862-74 Available at:

Hotchkiss RS, Monneret G \& Payen D (2013b) Immunosuppression in sepsis: A novel understanding of the disorder and a new therapeutic approach. Lancet Infect. Dis. 13: 260-268

Houslay DM, Anderson KE, Chessa T, Kulkarni S, Fritsch R, Downward J, Backer JM, Stephens LR $\&$ Hawkins PT (2016) Coincident signals from GPCRs and receptor tyrosine kinases are uniquely transduced by PI3K $\beta$ in myeloid cells. Sci. Signal. 9: 1-13

Huber-Lang M, Sarma VJ, Lu KT, McGuire SR, Padgaonkar VA, Guo RF, Younkin EM, Kunkel RG, Ding J, Erickson R, Curnutte JT \& Ward PA (2001) Role of C5a in multiorgan failure during sepsis. J. Immunol. 166: 1193-1199

Huber-Lang MS, Riedeman NC, Sarma JV, Younkin EM, McGuire SR, Laudes IJ, Lu KT, Guo RF, Neff TA, Padgaonkar VA, Lambris JD, Spruce L, Mastellos D, Zetoune FS \& Ward PA (2002a) Protection of innate immunity by C5aR antagonist in septic mice. FASEB J. 16: 1567-1574

Huber-Lang MS, Younkin EM, Sarma J V., McGuire SR, Lu KT, Guo RF, Padgaonkar VA, Curnutte JT, Erickson R \& Ward PA (2002b) Complement-Induced Impairment of Innate Immunity During Sepsis. J. Immunol. 169: 3223-3231

Jann NJ, Schmaler M, Ferracin F \& Landmann R (2011) TLR2 enhances NADPH oxidase activity and killing of Staphylococcus aureus by PMN. Immunol. Lett. 135: 17-23

Juss JK, House D, Amour A, Begg M, Herre J, Storisteanu DML, Hoenderdos K, Bradley G, Lennon M, Summers C, Hessel EM, Condliffe A \& Chilvers ER (2016) Acute respiratory distress syndrome neutrophils have a distinct phenotype and are resistant to phosphoinositide 3-kinase inhibition. Am. J. Respir. Crit. Care Med. 194: 961-973

Kobayashi SD, Voyich JM, Buhl CL, Stahl RM \& DeLeo FR (2002) Global changes in gene expression by human polymorphonuclear leukocytes during receptor-mediated phagocytosis: cell fate is regulated at the level of gene expression. Proc. Natl. Acad. Sci. 99: 6901-6906

Lacoma A, Cano V, Moranta D, Regueiro V, Domínguez-Villanueva D, Laabei M, González-Nicolau 
M, Ausina V, Prat C \& Bengoechea JA (2017) Investigating intracellular persistence of

Staphylococcus aureus within a murine alveolar macrophage cell line. Virulence 8: 1761-1775

Landelle C, Lepape A, Voirin N, Tognet E, Venet F, Bohe J, Vanhems P \& Monneret G (2010) Low monocyte human leukocyte antigen-DR is independently associated with nosocomial infections after septic shock. Intensive Care Med. 36: 1859-1866

Lee H, Whitfeld PL \& Mackay CR (2008) Receptors for complement C5a. The importance of C5aR and the enigmatic role of C5L2. Immunol. Cell Biol. 86: 153-160

Levin R, Grinstein S \& Canton J (2016) The life cycle of phagosomes: formation, maturation, and resolution. Immunol. Rev. 273: 156-179

Li L, Pian Y, Chen S, Hao H, Zheng Y, Zhu L, Xu B, Liu K, Li M, Jiang H \& Jiang Y (2016) Phenolsoluble modulin $\alpha 4$ mediates Staphylococcus aureus-associated vascular leakage by stimulating heparin-binding protein release from neutrophils. Sci. Rep. 6: 1-12

Lohse MJ, Hein P, Hoffmann C, Nikolaev VO, Vilardaga JP \& Bunemann M (2008) Kinetics of Gprotein-coupled receptor signals in intact cells. Br. J. Pharmacol. 153: 125-132

Lord JM, Midwinter MJ, Chen YF, Belli A, Brohi K, Kovacs EJ, Koenderman L, Kubes P \& Lilford RJ (2014) The systemic immune response to trauma: An overview of pathophysiology and treatment. Lancet 384: $1455-1465$

Luerman G, Uriarte S, Rane M \& McLeish K (2010) Application of proteomics to neutrophil biology. J. Proteomics 73: 552-561

Mazaki Y, Hashimoto S, Tsujimura T, Morishige M, Hashimoto A, Aritake K, Yamada A, Nam J-M, Kiyonari H, Nakao K \& Sabe H (2006) Neutrophil direction sensing and superoxide production linked by the GTPase-activating protein GIT2. Nat. Immunol. 7: 724-31

McGovern NN, Cowburn AS, Porter L, Walmsley SR, Summers C, Thompson A a R, Anwar S, Willcocks LC, Whyte MKB, Condliffe AM \& Chilvers ER (2011) Hypoxia selectively inhibits respiratory burst activity and killing of Staphylococcus aureus in human neutrophils. $J$. Immunol. 186: 453-463

McLeish KR, Merchant ML, Klein JB \& Ward RA (2013) Technical note: proteomic approaches to fundamental questions about neutrophil biology. J. Leukoc. Biol. 94: 683-692

Meakins JL, Pietsch JB, Bubenick O, Kelly R, Rode H, Gordon J \& MacLean LD (1977) Delayed hypersensitivity: indicator of acquired failure of host defenses in sepsis and trauma. Ann. Surg. 186: $241-250$

Mollnes TE, Brekke O, Fung M, Fure H, Christiansen D, Bergseth G, Videm V, Lappegård KT, Köhl J \& Lambris JD (2002) Essential role of the C5a receptor in E coli - induced oxidative burst and phagocytosis revealed by a novel lepirudin-based human whole blood model of inflammation. Blood 100: 1869-1877

Muschter S, Berthold T, Bhardwaj G, Hammer E, Dhople VM, Wesche J, Reil A, Bux J, Bakchoul T, Steil L, Greinacher A \& Völker U (2015) Mass spectrometric phosphoproteome analysis of small-sized samples of human neutrophils. Clin. Chim. Acta 451: 199-207

Naufer A, Hipolito VEBB, Ganesan S, Prashar A, Zaremberg V, Botelho RJ \& Terebiznik MR (2018) $\mathrm{pH}$ of endophagosomes controls association of their membranes with Vps34 and PtdIns(3)P levels. J. Cell Biol. 217: 329-346

Papachristou EK, Kishore K, Holding AN, Harvey K, Roumeliotis TI, Chilamakuri CSR, Omarjee S, Chia KM, Swarbrick A, Lim E, Markowetz F, Eldridge M, Siersbaek R, D’Santos CS \& Carroll JS (2018) A quantitative mass spectrometry-based approach to monitor the dynamics of endogenous chromatin-associated protein complexes. Nat. Commun. 9: 2311

Perianayagam MC, Balakrishnan VS, King AJ, Pereira BJG \& Jaber BL (2002) C5a delays apoptosis of human neutrophils by a phosphatidylinositol 3-kinase-signaling pathway. Kidney Int. 61: 456-463

Perianayagam MC, Balakrishnan VS, Pereira BJG \& Jaber BL (2004) C5a delays apoptosis of human neutrophils via an extracellular signal-regulated kinase and Bad-mediated signalling pathway. Eur. J. Clin. Invest. 34: 50-56

Perez-Riverol Y, Csordas A, Bai J, Bernal-Llinares M, Hewapathirana S, Kundu DJ, Inuganti A, Griss J, Mayer G, Eisenacher M, Pérez E, Uszkoreit J, Pfeuffer J, Sachsenberg T, Yilmaz S, Tiwary S, Cox J, Audain E, Walzer M, Jarnuczak AF, Ternent T, Brazma A, 
Vizcaíno JA (2019). The PRIDE database and related tools and resources in 2019: improving support for quantification data. Nucleic Acids Res 47(D1):D442-D450

Pilsczek FH, Salina D, Poon KKH, Fahey C, Yipp BG, Sibley CD, Robbins SM, Green FHY, Surette MG, Sugai M, Bowden MG, Hussain M, Zhang K \& Kubes P (2010) A Novel Mechanism of Rapid Nuclear Neutrophil Extracellular Trap Formation in Response to Staphylococcus aureus . J. Immunol. 185: 7413-7425

Pinder EM, Rostron AJ, Hellyer TP, Ruchaud-Sparagano M-H, Scott J, Macfarlane JG, Wiscombe S, Widdrington JD, Roy AI, Linnett VC, Baudouin S V, Wright SE, Chadwick T, Fouweather T, Juss JK, Chilvers ER, Bowett SA, Parker J, McAuley DF, Conway Morris A, et al (2018) Randomised controlled trial of GM-CSF in critically ill patients with impaired neutrophil phagocytosis. Thorax 73: 918-25 A

Rorvig S, Ostergaard O, Heegaard NHH \& Borregaard N (2013) Proteome profiling of human neutrophil granule subsets, secretory vesicles, and cell membrane: correlation with transcriptome profiling of neutrophil precursors. J. Leukoc. Biol. 94: 711-721

RStudio Team (2016) RStudio: Integrated Development for R Boston, MA: RStudio, Inc. Available at: http://www.rstudio.com/

Schmidt T, Brodesser A, Schnitzler N, Gruger T, Brandenburg K, Zinserling J \& Zundorf J (2015) CD66b overexpression and loss of C5a receptors as surface markers for Staphylococcus aureusinduced neutrophil dysfunction. PLoS One 10: 1-18

Scicluna BP, Klein Klouwenberg PMC, Van Vught LA, Wiewel MA, Ong DSY, Zwinderman AH, Franitza M, Toliat MR, Nurnberg P, Hoogendijk AJ, Horn J, Cremer OL, Schultz MJ, Bonten MJ, Van Der Poll T, Nürnberg P, Hoogendijk AJ, Horn J, Cremer OL, Schultz MJ, et al (2015) A molecular biomarker to diagnose community-acquired pneumonia on intensive care unit admission. Am. J. Respir. Crit. Care Med. 192: 826-835

Scott J, Harris GJ, Pinder EM, Macfarlane JG, Hellyer TP, Rostron AJ, Conway Morris A, Thickett DR, Perkins GD, McAuley DF, Widdrington JD, Wiscombe S, Baudouin S V., Roy AI, Linnett VC, Wright SE, Ruchaud-Sparagano M-H \& Simpson AJ (2015) Exchange protein directly activated by cyclic AMP (EPAC) activation reverses neutrophil dysfunction induced by $\beta 2-$ agonists, corticosteroids, and critical illness. J. Allergy Clin. Immunol. 137: 535-44

Sorkin A \& Von Zastrow M (2009) Endocytosis and signalling: Intertwining molecular networks. Nat. Rev. Mol. Cell Biol. 10: 609-622

Suire S, Condliffe AM, Ferguson GJ, Ellson CD, Guillou H, Davidson K, Welch H, Coadwell J, Turner M, Chilvers ER, Hawkins PT \& Stephens L (2006) Gbetagammas and the Ras binding domain of p110gamma are both important regulators of PI(3)Kgamma signalling in neutrophils. Nat. Cell Biol. 8: 1303-9

Tak T, Rygiel TP, Karnam G, Bastian OW, Boon L, Viveen M, Coenjaerts FE, Meyaard L, Koenderman L \& Pillay J (2017) Neutrophil mediated suppression of influenza-induced pathology requires CD11b/CD18 (MAC-1). Am. J. Respir. Cell Mol. Biol. 58: 492-499

The Uniprot Consortium (2019) UniProt: A worldwide hub of protein knowledge. Nucleic Acids Res. 47: D506-D515

Unnewehr H, Rittirsch D, Sarma JV, Flierl MA, Perl M, Denk S, Weiss M, Schneider ME, Monk PN, Neff T, Mihlan M, Barth H, Ward PA \& Huber-Lang M (2013) Changes and Regulation of the C5a Receptor on Neutrophils during Septic Shock in Humans. J. Immunol. 190: 1-11

Venet F \& Monneret G (2018) Advances in the understanding and treatment of sepsis-induced immunosuppression. Nat. Rev. Nephrol. 14: 121-137

Vincent J-L, Rello J, Marshall J, Eliiezer S, Anzueto A, Martin CD, Moreno R, Lipman J, Gomersall C, Sakr Y \& Reinhart K (2009) International Study of the Prevalence and Outcomes of Infection in Intensive Care Units (EPIC II). JAMA 302: 2323-2329

Vincent J-L, Sakr Y, Sprung CL, Ranieri VM, Reinhart K, Gerlach H, Moreno R, Carlet J, Le Gall JR \& Payen D (2006) Sepsis in European intensive care units: results of the SOAP study. Crit. Care Med. 34: 344-353

van Vught LA, Klein Klouwenberg PMC, Spitoni C, Scicluna BP, Wiewel MA, Horn J, Schultz MJ, Nürnberg P, Bonten MJM, Cremer OL \& van der Poll T (2016) Incidence, Risk Factors, and Attributable Mortality of Secondary Infections in the Intensive Care Unit After Admission for Sepsis. JAMA 315: 1469-79 
Ward PA (2004) The dark side of C5a in sepsis. Nat. Rev. Immunol. 4: 133-142

Ward PA \& Newman LJ (1969) A Neutrophil Chemotactic Factor from Human C5. J. Immunol. 102: 93-99

Wickham M (2016) ggplot2: Elegant Graphics for Data Analysis. New York, USA: Springer-Verlag

Zhou Y, Zhou B, Pache L, Chang M, Khodabakhshi AH, Tanaseichuk O, Benner C \& Chanda SK

(2019) Metascape provides a biologist-oriented resource for the analysis of systems-level datasets. Nat. Commun. 10: 1523 


\section{Tables}

Table I: Differentially phosphorylated proteins between C5a and control-treated neutrophils exposed to $S$. aureus.

All 19 phosphoproteins with Bonferroni adjusted p-values $<0.05$ for difference in phosphorylation status between the Control plus $S$. aureus vs C5a plus S. aureus conditions. Subcellular location and function manually annotated from Uniprot database (The Uniprot Consortium, 2019).

\begin{tabular}{|c|c|c|}
\hline Protein name & $\begin{array}{l}\text { Sub-cellular } \\
\text { localisation }\end{array}$ & Functional role \\
\hline \multicolumn{3}{|l|}{ Endosomal/phagosomal } \\
\hline $\begin{array}{l}\text { Zinc finger FYVE domain- } \\
\text { containing protein } 16 \text { (ZFYVE16) }\end{array}$ & Early Endosomes & $\begin{array}{l}\mathrm{PI}(3) \mathrm{P} \text { binding FYVE domain, } \\
\text { found on early endosomes, targets } \\
\text { TOM1 to endosomes }\end{array}$ \\
\hline Target of Myb protein 1 (TOM1) & $\begin{array}{l}\text { Endosomes/azurophil } \\
\text { granule membrane } \\
\text { (neutrophil) }\end{array}$ & Known interactor with ZFYVE16 \\
\hline $\begin{array}{l}\text { V-type proton ATPase subunit G } 1 \\
\text { (ATP6V1G1) }\end{array}$ & Endosomes/phagosomes & $\begin{array}{l}\text { Proton channel acidifying vacuolar } \\
\text { structures }\end{array}$ \\
\hline Wiskott-Aldrich protein (WAS) & Cytoplasm, phagosomes & $\begin{array}{l}\text { RhoGTPase effector and actin } \\
\text { polymerisation }\end{array}$ \\
\hline Epsin-1 (EPN1) & $\begin{array}{l}\text { Plasma membrane, } \\
\text { clathrin coated pits }\end{array}$ & $\begin{array}{l}\text { Regulates receptor-mediated } \\
\text { endocytosis, } \mathrm{PI}(4,5) \mathrm{P} \text { binding }\end{array}$ \\
\hline \multicolumn{3}{|l|}{ Lysosomes } \\
\hline $\begin{array}{l}\text { Ubiquitin carboxyl-terminal } \\
\text { hydrolase } 5 \text { (USP5) }\end{array}$ & $\begin{array}{l}\text { Lysosome and } \\
\text { cytoplasm }\end{array}$ & Deubiquitination \\
\hline $\begin{array}{l}\text { Synaptic vesicle membrane protein } \\
\text { VAT-1 homolog (VAT1) }\end{array}$ & $\begin{array}{l}\text { Lysosomes/azurophil } \\
\text { granule (neutrophil) }\end{array}$ & Neutrophil degranulation \\
\hline \multicolumn{3}{|l|}{ Nuclear } \\
\hline $\begin{array}{l}\text { Nuclear pore complex protein } 153 \\
\text { (NUP153) }\end{array}$ & Nuclear membrane & $\begin{array}{l}\text { Phosphorylation occurs during } \\
\text { nuclear membrane disassembly }\end{array}$ \\
\hline Lamin-B1 (LMNB1) & Nuclear membrane & $\begin{array}{l}\text { Phosphorylation occurs during } \\
\text { nuclear membrane disassembly }\end{array}$ \\
\hline Histone H3.3 (H3F3A) & Nucleus & Histone protein \\
\hline Protein SGT1 homolog (SUGT1) & $\begin{array}{l}\text { Nucleus and } \\
\text { kinteochore }\end{array}$ & Mitosis \\
\hline $\begin{array}{l}\text { Sperm-associated antigen } 7 \\
\text { (SPAG7) }\end{array}$ & Nucleus & Nucleic acid binding \\
\hline $\begin{array}{l}\text { Splicing factor U2AF } 35 \mathrm{kDa} \\
\text { subunit (U2AF1) }\end{array}$ & Nucleus & RNA splicing \\
\hline $\begin{array}{l}\text { Chromatin complexes subunit } \\
\text { BAP18 (BAP18) }\end{array}$ & Nucleus & Chromatin organisation \\
\hline \multicolumn{3}{|l|}{ Nuclear/Cytoplasmic proteins } \\
\hline $\begin{array}{l}\text { Serine/threonine-protein kinase } 3 \\
\text { (STK3) }\end{array}$ & Nucleus/cytoplasm & $\begin{array}{l}\text { Cycles between nucleus and } \\
\text { cytoplasm, influenced by } \\
\text { phosphorylation status under } \\
\text { control of caspases }\end{array}$ \\
\hline $\begin{array}{l}\text { Transforming acidic coiled-coil- } \\
\text { containing protein } 1 \text { (TACC1) }\end{array}$ & $\begin{array}{l}\text { Nucleus, centerosome, } \\
\text { microtubules }\end{array}$ & $\begin{array}{l}\text { Microtubule organisation and } \\
\text { mitotic spindle formation }\end{array}$ \\
\hline $\begin{array}{l}\text { Serine/threonine-protein kinase } \\
\text { TAO2 (TAOK2) }\end{array}$ & Nucleus/Cytoskeleton & $\begin{array}{l}\text { Regulation of actin cytoskeleton } \\
\text { and MAP kinase activity }\end{array}$ \\
\hline \multicolumn{3}{|l|}{ Endoplasmic reticulum } \\
\hline Protein lunapark (LNP) & Endoplasmic reticulum & Phosphorylated during mitosis \\
\hline
\end{tabular}


bioRxiv preprint doi: https://doi.org/10.1101/2020.01.17.907618; this version posted February 25, 2020. The copyright holder for this preprint (which was not certified by peer review) is the author/funder, who has granted bioRxiv a license to display the preprint in perpetuity. It is made available under aCC-BY 4.0 International license.

\begin{tabular}{|l|l|l|}
\hline $\begin{array}{l}\text { Thioredoxin-related transmembrane } \\
\text { protein 1 (TMX1) }\end{array}$ & Endoplasmic reticulum & Cell response to oxidative stress \\
\hline
\end{tabular}




\section{Figure legends}

Figure 1: C5a induces a prolonged defect in neutrophil phagocytosis of bacteria

A and B: Isolated neutrophils were pre-treated with $100 \mathrm{nM} \mathrm{C5a}$ or vehicle control for $60 \mathrm{~min}$ before incubation with $S$. aureus (A) or E. coli (B) bioparticles. Data are presented as the median phagocytic index for each condition for $\mathrm{n}=7$ (A) or 6 (B) independent donors, ${ }^{*} P=0.016$ (A) and 0.031 (B) by Wilcoxon's matched-pairs signed rank test.

C: Neutrophils were pulsed with $100 \mathrm{nM} \mathrm{C5a}$ or PBS control for the indicated periods of time, followed by 2 washes. $S$. aureus bioparticles were then added and cells were incubated for the indicated time points. Data are presented as the mean and SD of the phagocytic index of C5a-treated cells relative to their paired vehicle control for $\mathrm{n}=5$ independent experiments. $P<0.0001$ for time and $P=0.0186$ for treatment by two-way ANOVA. ${ }^{* * *} P=0.0001 * * * * P<0.0001$ by Dunnett's multiple comparison test.

D: Data are presented as the mean and SD of the percentage of DRAQ7 positive, dead cells for $\mathrm{n}=5$ independent experiments. $P=0.378$ for time and $P=0.349$ for treatment by two-way ANOVA.

E: Anticoagulated whole blood was pre-treated with $300 \mathrm{nM} \mathrm{C5a}$ or control for the indicated duration before phagocytosis was measured as previously indicated. Data are presented as the mean and SD of the cumulative phagocytic index for 4 independent experiments. $P<0.0001$ by two-way ANOVA, $* * * * P<0.0001, * * * P<0.001$ by Sidak's multiple comparisons test.

F: S. aureus particles were incubated with isolated PMNs in the presence of $100 \mathrm{nM} \mathrm{C5a}$ or PBS added at the indicated time points, with time 0 representing the time of addition of $S$. aureus bioparticles. Experiments proceeded for the indicated time points and phagocytic index quantified. Data are presented as the mean and SD of the phagocytic index of C5a-treated cells relative to their paired vehicle control for $\mathrm{n}=5$ independent experiments. $P<0.0001$ for time and $P=0.0186$ for treatment by two-way ANOVA. $* * * * P<0.0001$ by Dunnett's multiple comparisons test.

Figure 2: S. aureus and C5a induce widespread changes in the neutrophil phosphoproteome

Heatmap of phosphoprotein intensity relative to baseline ( $\log _{2}$ fold change) across the four experimental conditions shows phosphoproteins with variance across conditions in the top $97.5^{\text {th }}$ centile with dendrograms clustered by Euclidean distance. Increased phosphoprotein expression is indicated in red, decreased in blue. Only phosphoproteins detected in all four donor samples were included.

Figure 3: C5a exposure induces persistent alteration in phosphoproteins across several pathways

A: Proteins with adjusted $P$-values $<0.05$ are shown in blue and the 20 proteins with the highest absolute $\log _{2}$ fold change are labelled. $P$-values were computed by limma-based linear models with Bonferroni's correction for multiple testing. B: Metascape(Zhou et al, 2019) enrichment heatmap showing functional clusters of phosphoproteins affected by C5a treatment.

Figure 4: S. aureus induces a marked alteration in the phosphoproteome that is significantly impacted by C5a exposure

A, B, D: Proteins with adjusted $P$-values $<0.05$ are shown in blue and the 20 proteins with the highest absolute $\log _{2}$ fold change are labelled. $P$-values were computed by limma-based linear models with Bonferroni's correction for multiple testing. C: Metascape(Zhou et al, 2019) enrichment heatmap showing functional clusters of phosphoproteins affected by S. aureus exposure. E: 
Metascape(Zhou et al, 2019) bar graph showing top non-redundant functional clusters of phosphoproteins enriched in the vehicle control/S. aureus condition versus $\mathrm{C} 5 \mathrm{a} / S$. aureus condition.

Figure 5: C5a induces an impairment in phagosomal acidification, distinct from the impairment in ingestion

A: Exemplar flow cytometry plots of whole blood pre-treated with vehicle control or bafilomycin A (60 min; 100nM) prior to exposure to $5 \mu \mathrm{g} / \mathrm{mL}$ co-labelled AF488/pHrodo red $S$. aureus for $120 \mathrm{~min}$. Both phagocytosis (x-axis) and phagosomal $\mathrm{pH}$ (y-axis) can be measured simultaneously in the same population of cells. $\mathrm{pHrodo}^{\mathrm{TM}}$ fluorescence increases with decreasing $\mathrm{pH}$, indicating phagosomal maturity as shown.

B: Conditions as in A. Data are shown as individual data points with mean for $\mathrm{n}=7$ individual donors. $P=0.016$ by Wilcoxon's test.

C: Whole blood was pre-treated with vehicle control or C5a (300 nM; 60 minutes) prior to exposure to phagocytosis probe for $180 \mathrm{~min}$. Phagocytosis without maturation (i.e. AF488 signal) is shown. Data are shown as mean and SD of $\mathrm{n}=5$ individual donors. $* * * * P<0.0001$ by repeated-measures two-way ANOVA with Bonferroni's multiple comparisons test.

D: Conditions as in C. The percentage of S. aureus particle positive (AF488+) cells with low pH (mature) and high pH (immature) phagosomes is shown for control and C5a-treated conditions. Data are shown as mean and $\mathrm{SD}$ of $\mathrm{n}=5$ individual donors. $* * * P<0.001$ by repeated-measures two-way ANOVA with Bonferroni's multiple comparisons test.

E: Whole blood was pre-treated with C5a, NHE-1 inhibitor $(5 \mu \mathrm{M})$, or both, then exposed to maturation probe for $60 \mathrm{~min}$. The percentage of AF488+ cells with high $\mathrm{pH}$ (immature) phagolysosomes is shown. Data are shown as individual data points with median from $\mathrm{n}=7$ individual donors. $P=0.0080$ by Friedman's test, $* P<0.05$ for Dunn's test of multiple comparisons, ns $=$ non-significant.

Figure 6: VPS34 inhibition impairs phagosomal acidification

Whole blood was pre-treated with vehicle control or VPS34IN1 $(1 \mu \mathrm{M} ; 60 \mathrm{~min})$ prior to addition of 5 $\mu \mathrm{g} / \mathrm{mL}$ maturation probe (A-D), or live $S$. aureus (E), for 120 minutes prior to analysis.

A: Percentage of neutrophils that have phagocytosed bioparticles. $P=0.31$ by Wilcoxon's test. $\mathrm{n}=6$ individual donors.

B: MFI of ingested particles, indicating relative quantity of phagocytosis. $P=0.03$. by Wilcoxon's test. $\mathrm{n}=6$ individual donors.

C: pHrodo $^{\mathrm{TM}}$ Median Fluorescent Intensity (MFI), indicating phagosomal acidification. $P=0.03$. by Wilcoxon's test. $\mathrm{n}=6$ individual donors.

D: After phagocytosis of live bacteria, human cells were lysed in alkaline $\mathrm{dH}_{2} \mathrm{O}$ and surviving bacteria were incubated overnight on blood agar. Bacterial survival was quantified by counting colonies. $P=0.03$ by paired t-test, $\mathrm{n}=5$ individual donors.

E-F: Whole blood was processed as above with quantification of phagocytosis (E) and acidification (F) at the indicated time points. There was a reduction in phagosomal acidification as shown but no change in percentage of cells that underwent phagocytosis. Data are shown as mean and SD of $n=5$ individual donors. $* * P=0.0058$ for drug treatment by repeated measures two-way ANOVA with Bonferroni's multiple comparisons test. 
Figure 7: Neutrophils from critically ill patients exhibit defective phagosomal acidification

A: Zymosan-based assay demonstrating differentially impaired phagocytosis in critically ill patients. Data are shown as individual patients/controls with median values indicated. $\mathrm{n}=6$ patients with dysfunctional neutrophils and 5 patients with functional neutrophils respectively. ** $P=0.004$ by Mann-Whitney U-test.

B: Neutrophil phagosomal acidification was assessed in whole blood from critically ill patients using the maturation probe. Patients were classed as dysfunctional using the assay from A. Data are shown as individual patients/controls with mean from $\mathrm{n}=6$ patients with dysfunctional neutrophils, 5 patients with functional neutrophils and 10 healthy controls respectively. $P=0.04$ by one-way ANOVA. $* * P<0.01$ by Holm-Sidak's test of multiple comparisons.

C, D: C5aR1 expression was assessed by flow cytometry and correlated (Spearman) with phagocytosis (C) and phagosomal acidification (D) for $\mathrm{n}=12$ patients. NB: One patient's cells did not adhere to tissue culture plastic for the zymosan assay, thus they could not be assigned to dysfunctional or non-dysfunctional groups shown in A and B. C5aR1 expression and maturation probe data was available to allow inclusion in correlation analyses in $\mathrm{C}$ and $\mathrm{D}$, hence the difference in numbers between these figures. 
Color Key

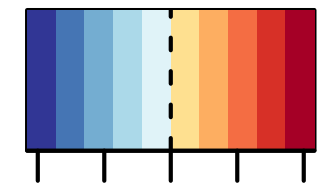

\section{$\begin{array}{lll}-2 & 0 & 2\end{array}$ \\ Log2FC phosphoprotein intensity}

bioRxiv preprint doi: https://doi.фrg/10.1101/2020.01.17.907618; this version posted February 25,2020. The copyright holder for this preprint (which was not certified by peer review) is the author/funder, who has granted bioRxiv a license to display the preprint in perpetuity. It is made
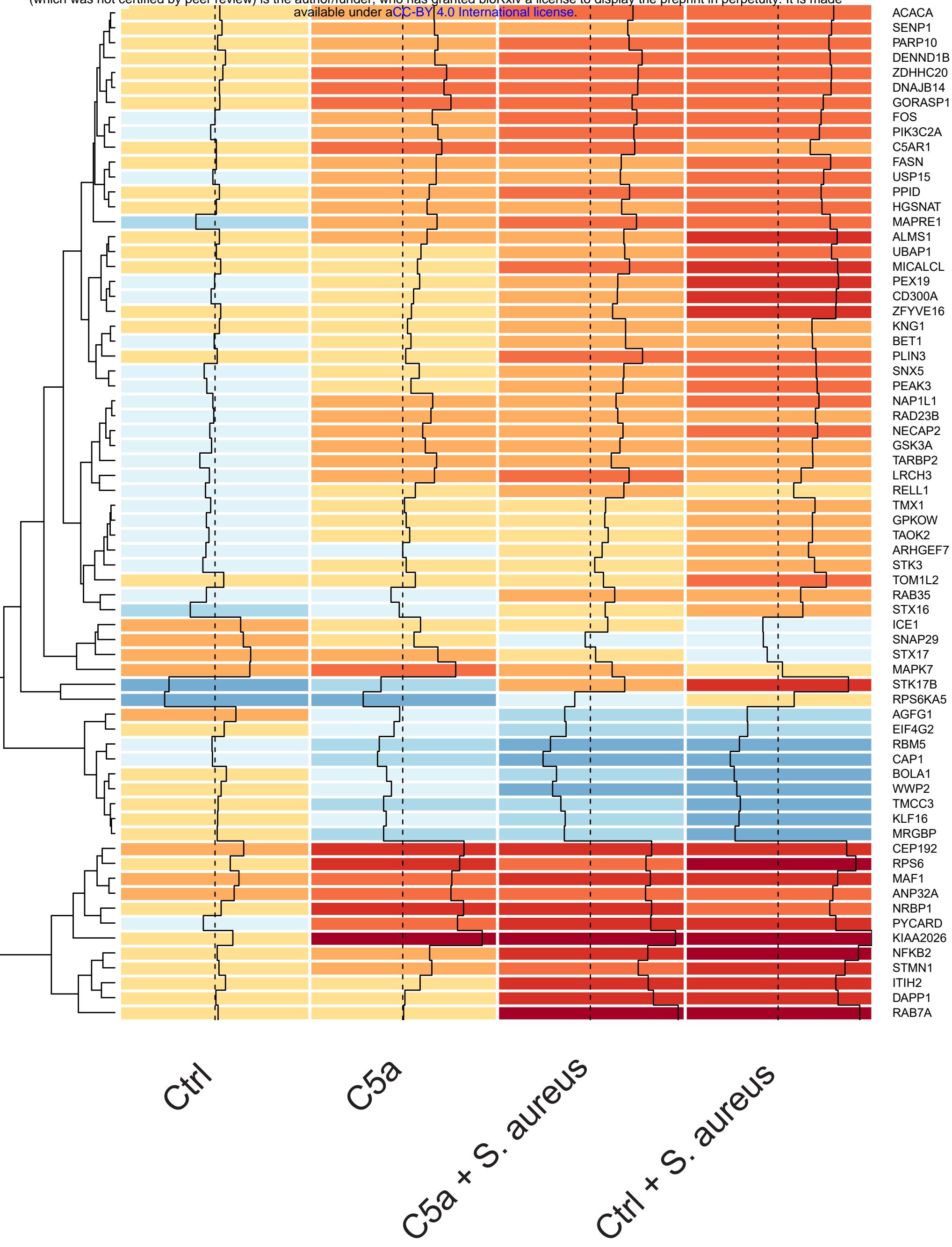


\section{A C5a vs ctrl}

bioRxiv preprint doi: https://doi.org/10.1101/2020.01.17.907618; this version posted February 25, 2020. The copyright holder for this preprint (which was not certified by peer review) is the author/funder, who has granted bioRxiv a license to display the preprint in perpetuity. It is made
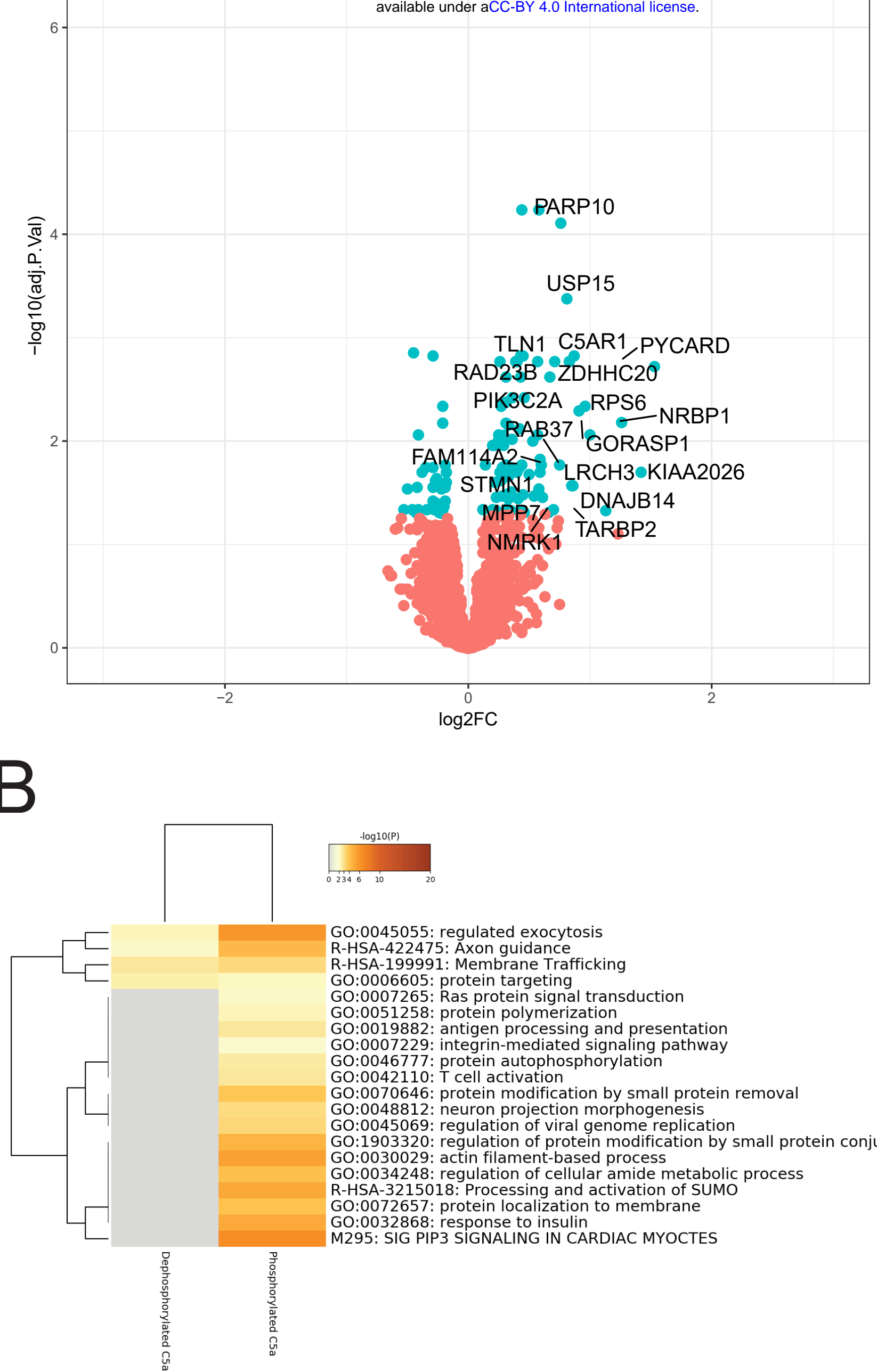

GO:0045055: regulated exocytosis

R-HSA-422475: Axon guidance

R-HSA-199991: Membrane Trafficking

GO:0006605: protein targeting

GO:0007265: Ras protein signal transduction

GO:0051258: protein polymerization

GO:0019882: antigen processing and presentation

GO:0007229: integrin-mediated signaling pathway

GO:0046777: protein autophosphorylation

GO:0042110: T cell activation

GO:0070646: protein modification by small protein removal

GO:0048812: neuron projection morphogenesis

GO:0045069: regulation of viral genome replication

GO:1903320: regulation of protein modification by small protein conjugation or removal GO:0030029: actin filament-based process

GO:0034248: regulation of cellular amide metabolic process

R-HSA-3215018: Processing and activation of SUMO

GO:0072657: protein localization to membrane

GO:0032868: response to insulin

M295: SIG PIP3 SIGNALING IN CARDIAC MYOCTES 
bioRxiv preprint doi: https://doi.org/10.1101/2020.01.17.907618; this version poste a february 25, 2020. The copyright holder for this preprint

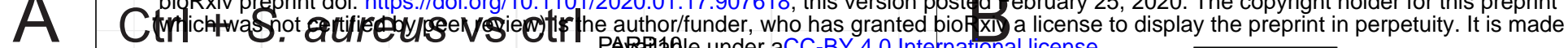

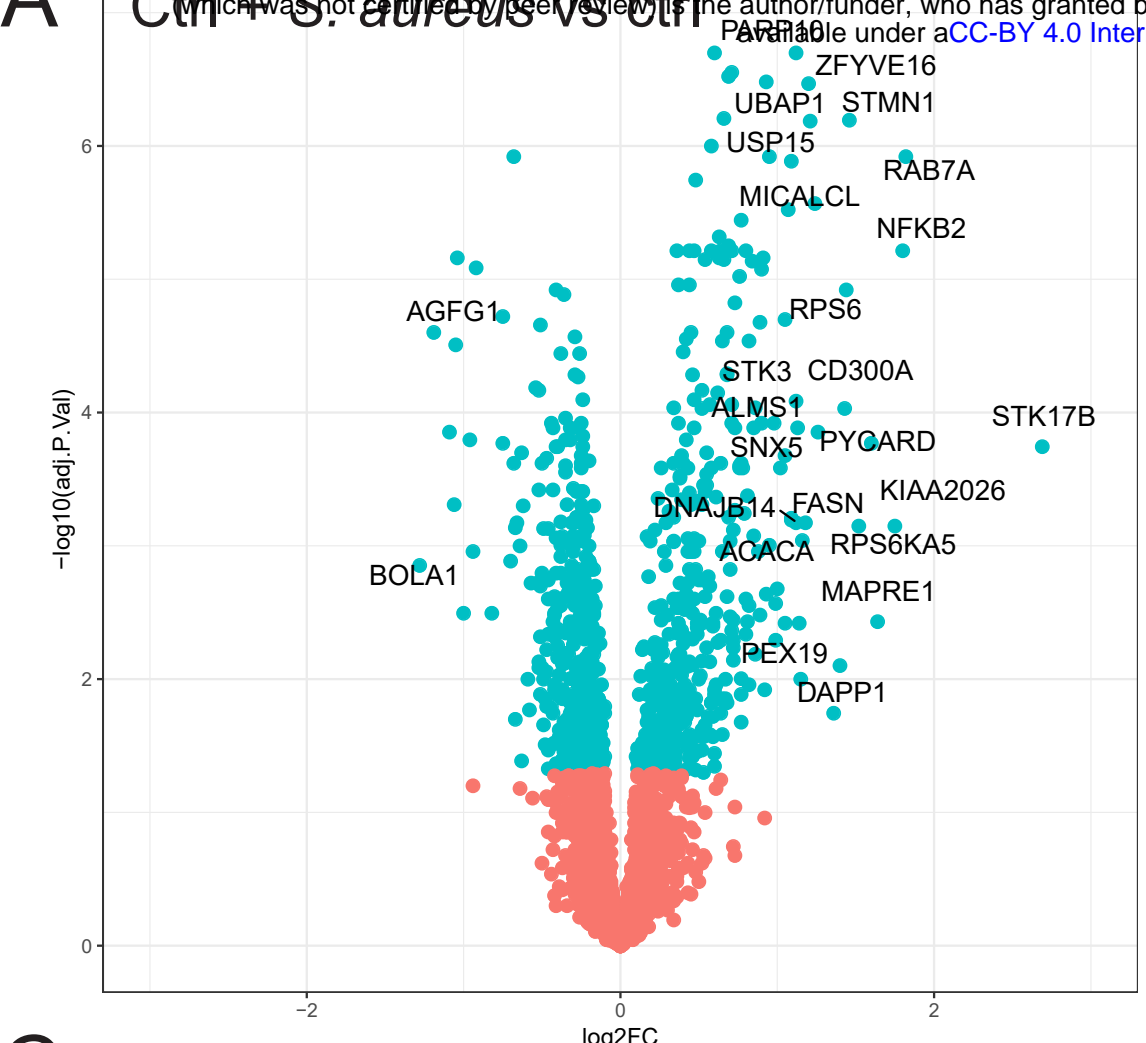

C
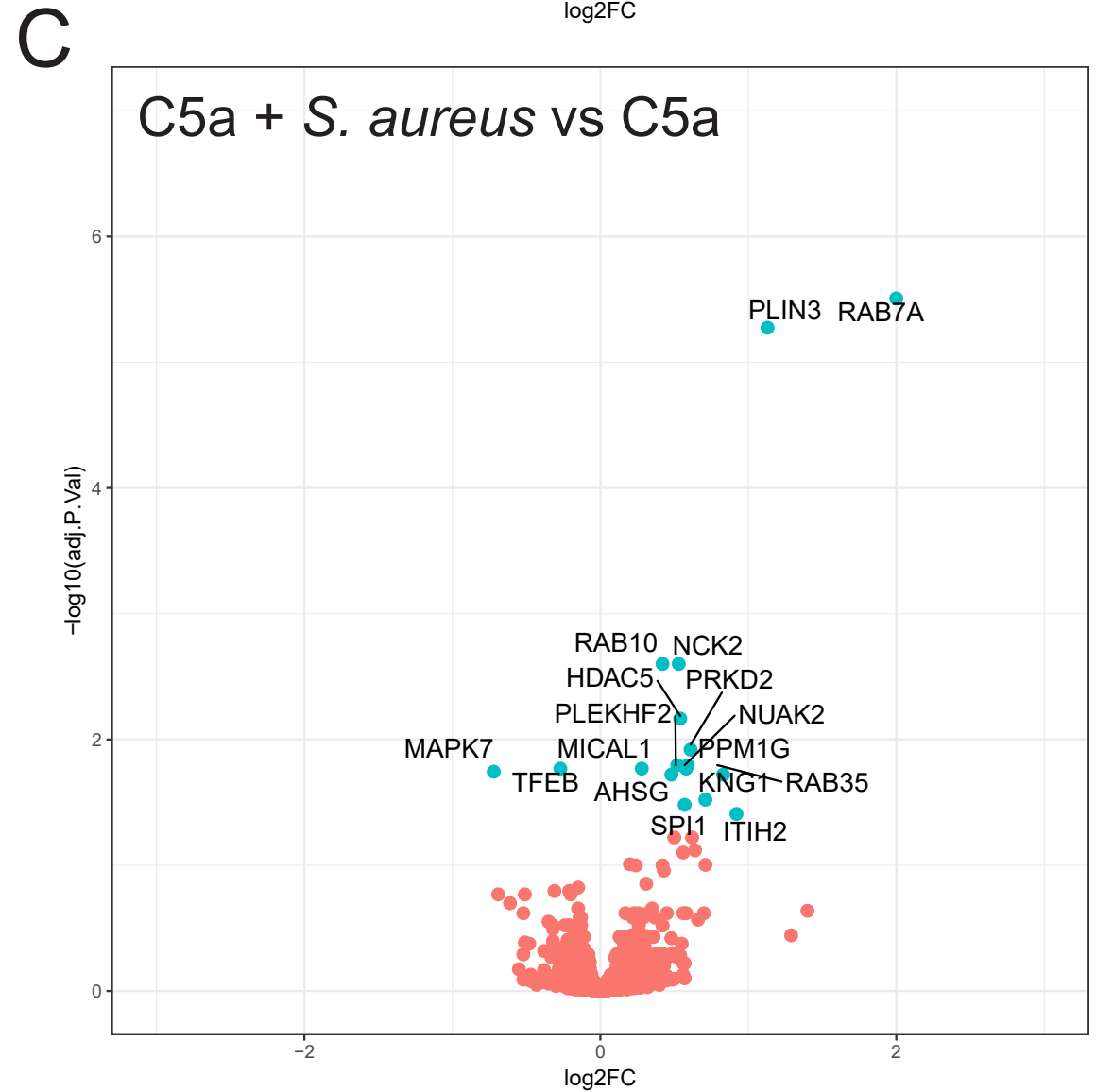
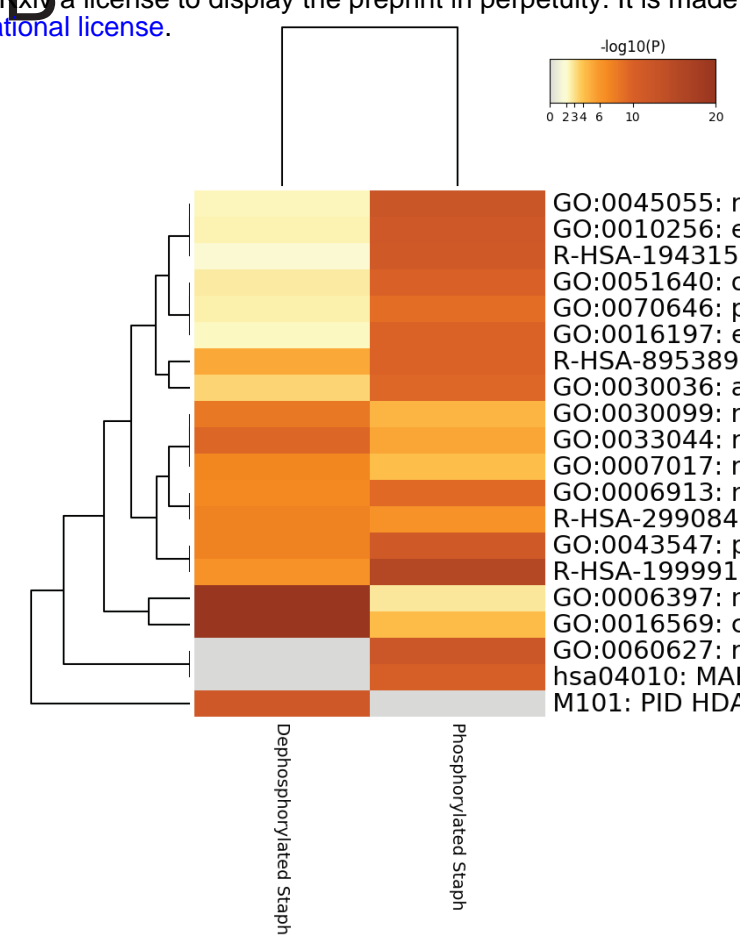

GO:0045055: regulated exocytosis GO:0010256: endomembrane system organization R-HSA-194315: Signaling by Rho GTPases GO:0051640: organelle localization GO:0070646: protein modification by small protein removal R-HSA-8953897: Cellular ransport

97: Cellular responses to external stimuli GO:0030036: actin cytoskeleton organization G:0030099: myeloid cell differentiation GO:0033044: regulation of chromosome organization GO:0007017: microtubule-based process R-HSA-2990846: nucleocytoplasmic transport R-HSA-2990846: SUMOylation GO:0043547: positive regulation of GTPase activity R-HSA-199991: Membrane Trafficking GO:0006397: mRNA processing ( Gesicle-mediated transport M101: PID HDAC CLASSI PATHWAY

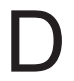

D

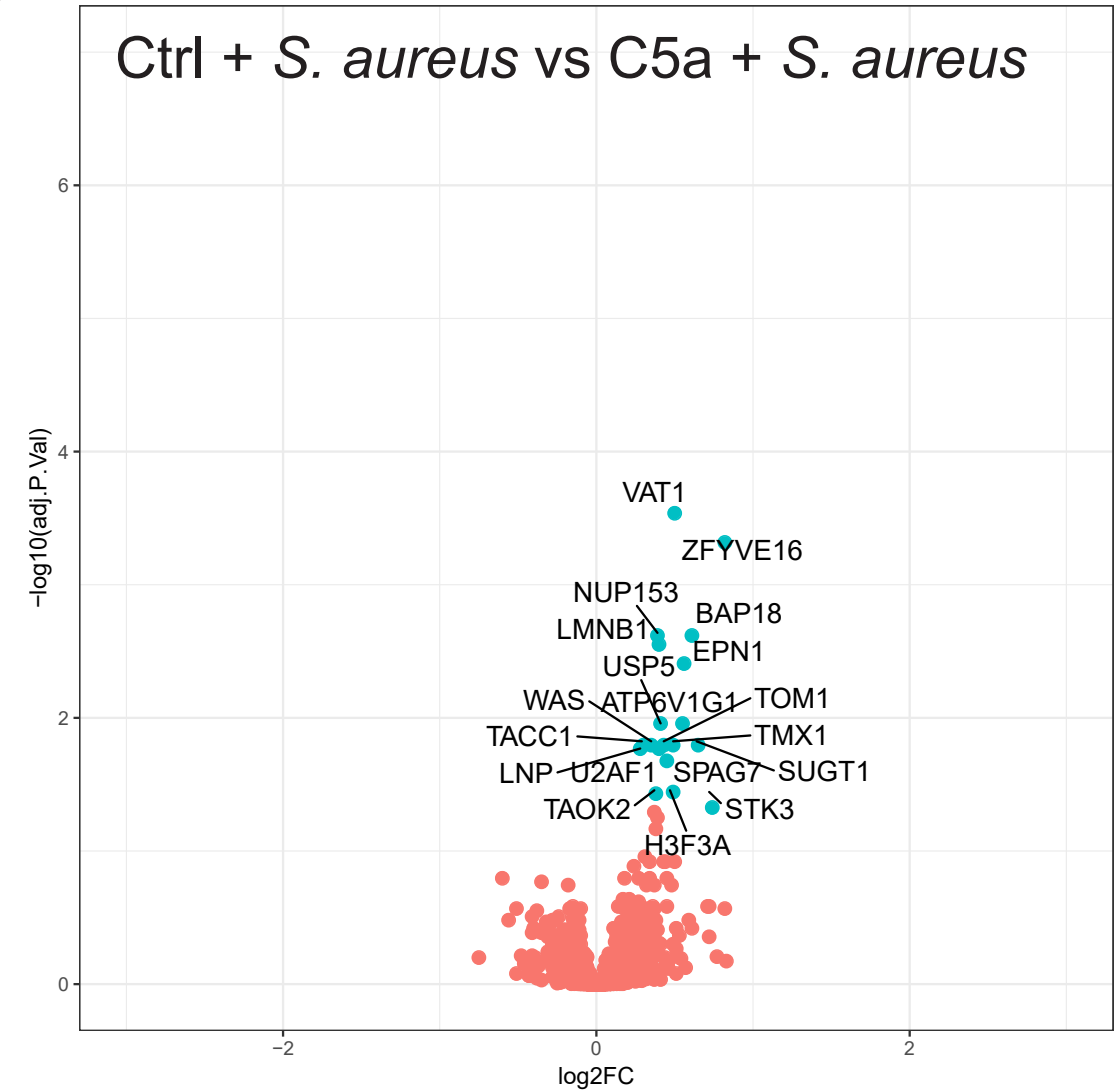




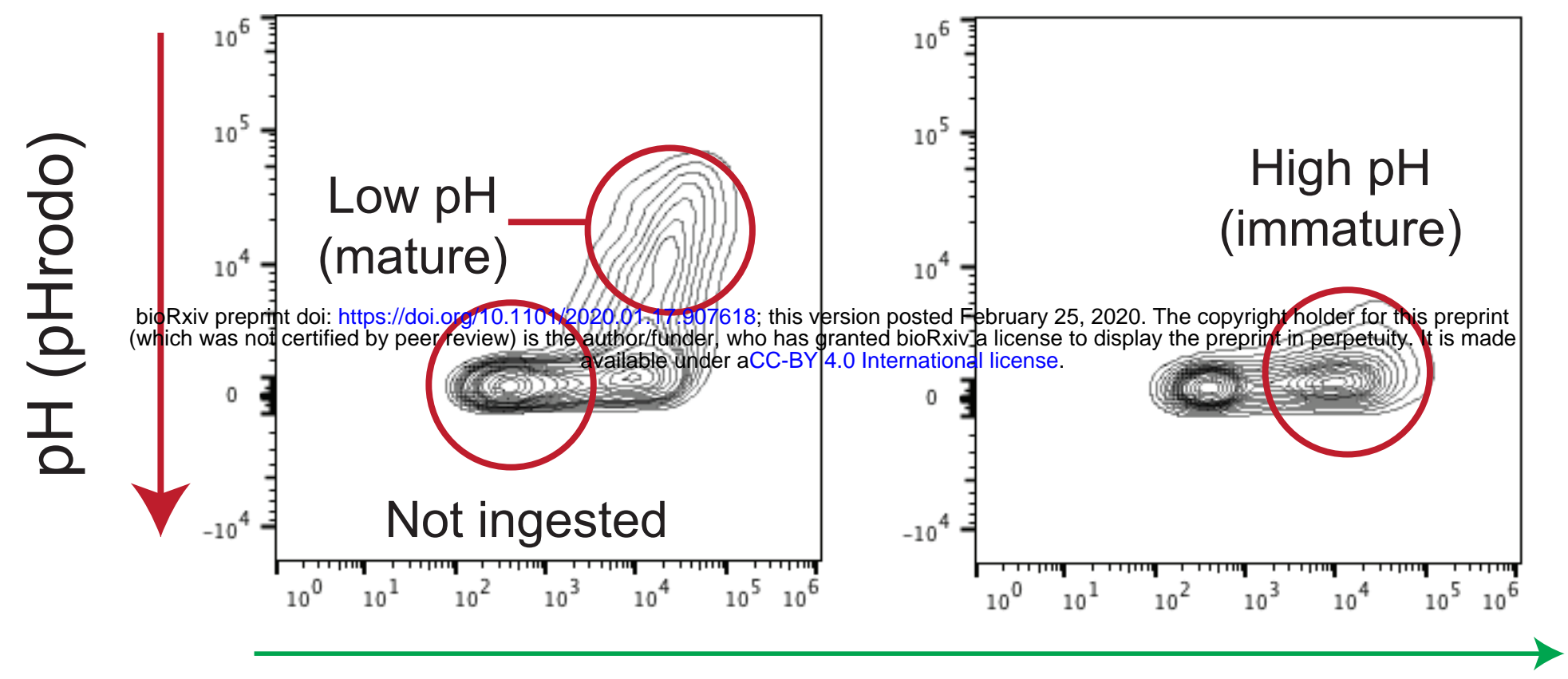

\section{Phagocytosis (AF488)}

B

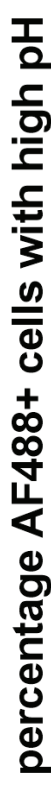

D

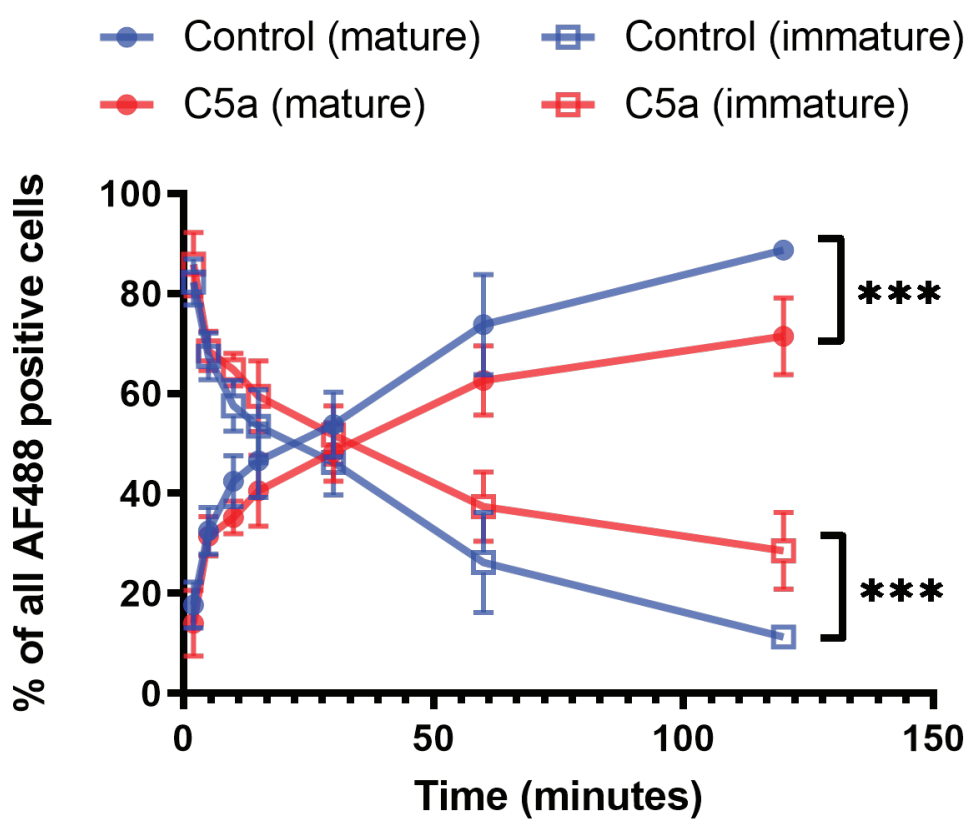

C

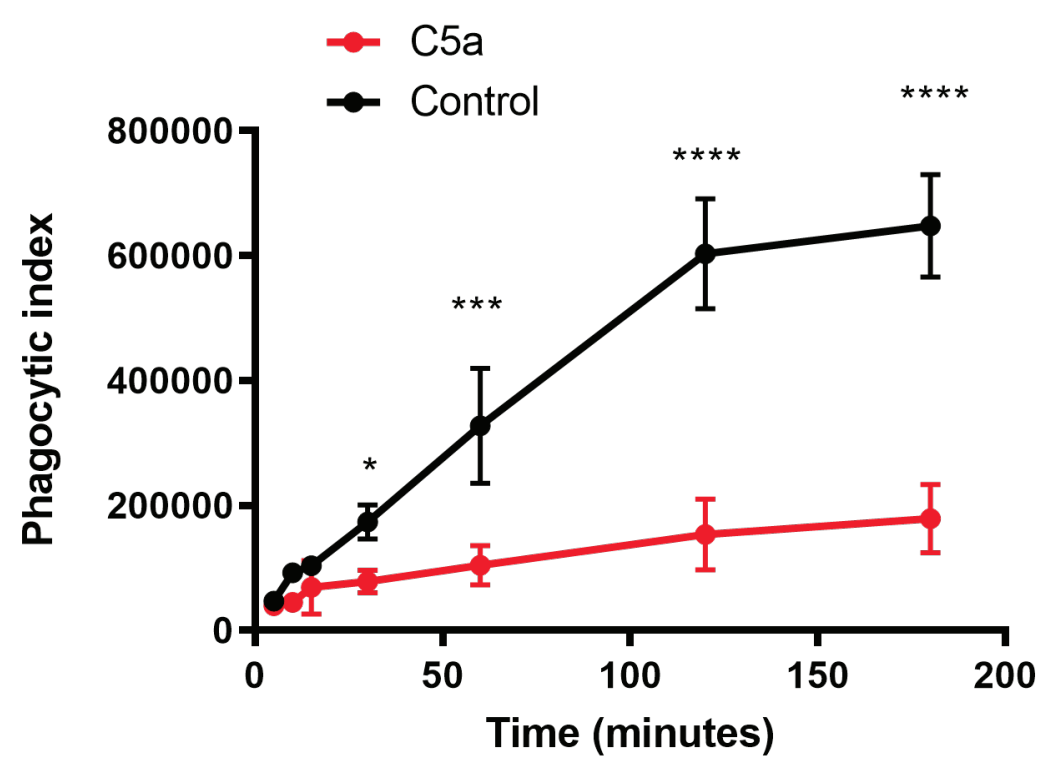

E

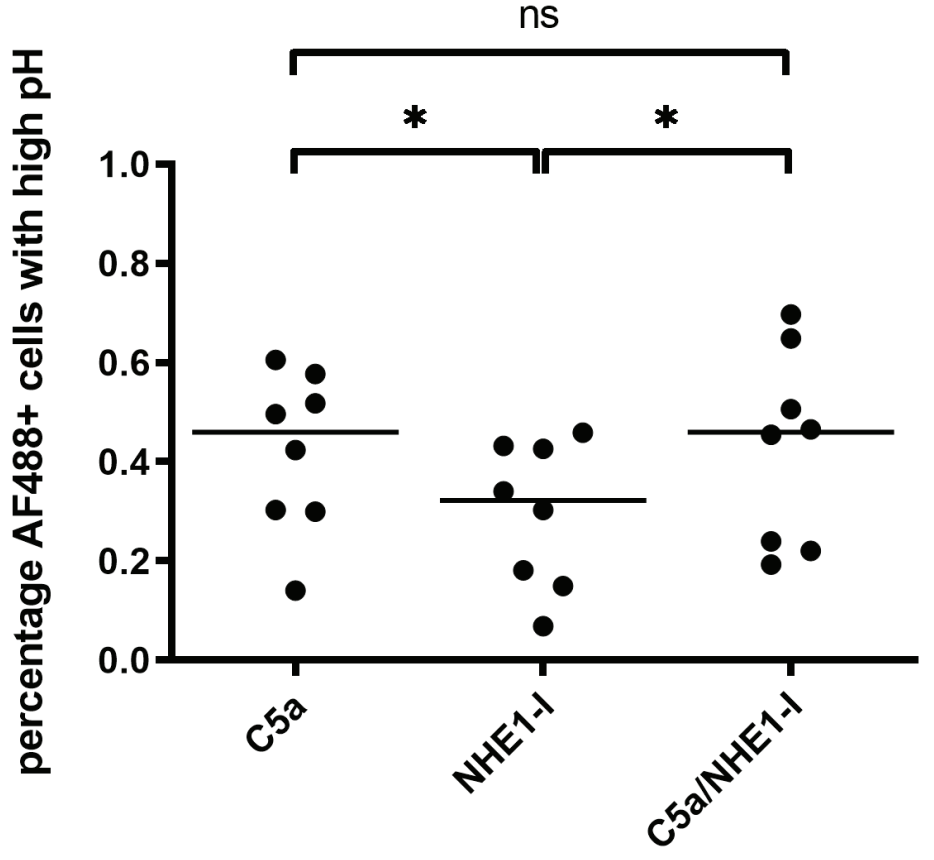


A

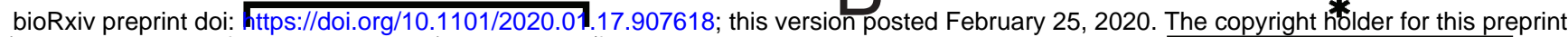

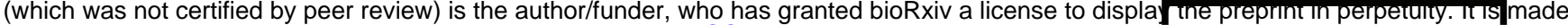
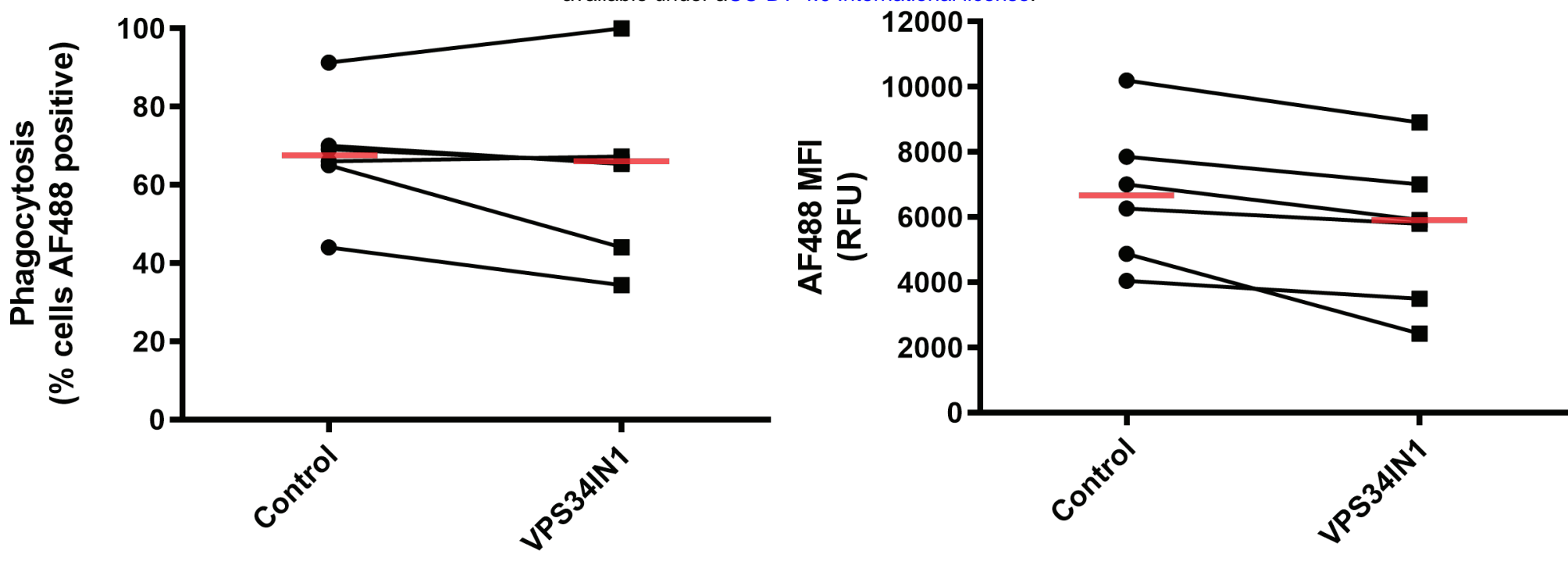

C

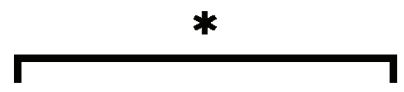

$D$
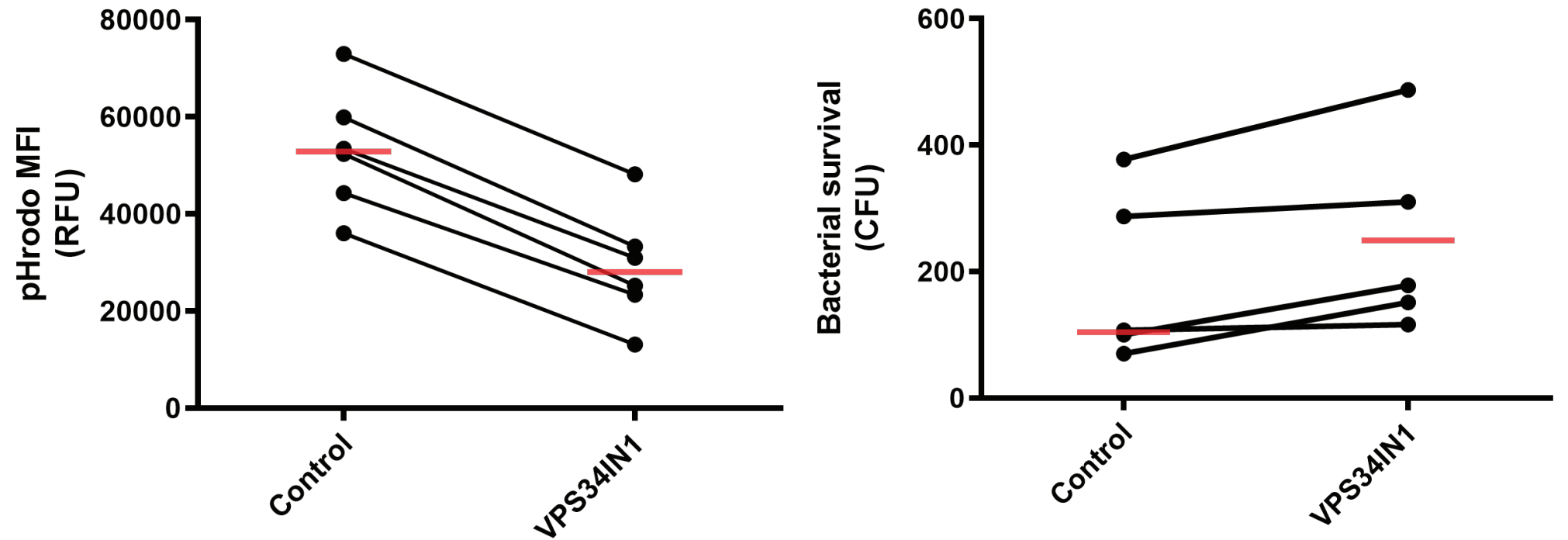

E
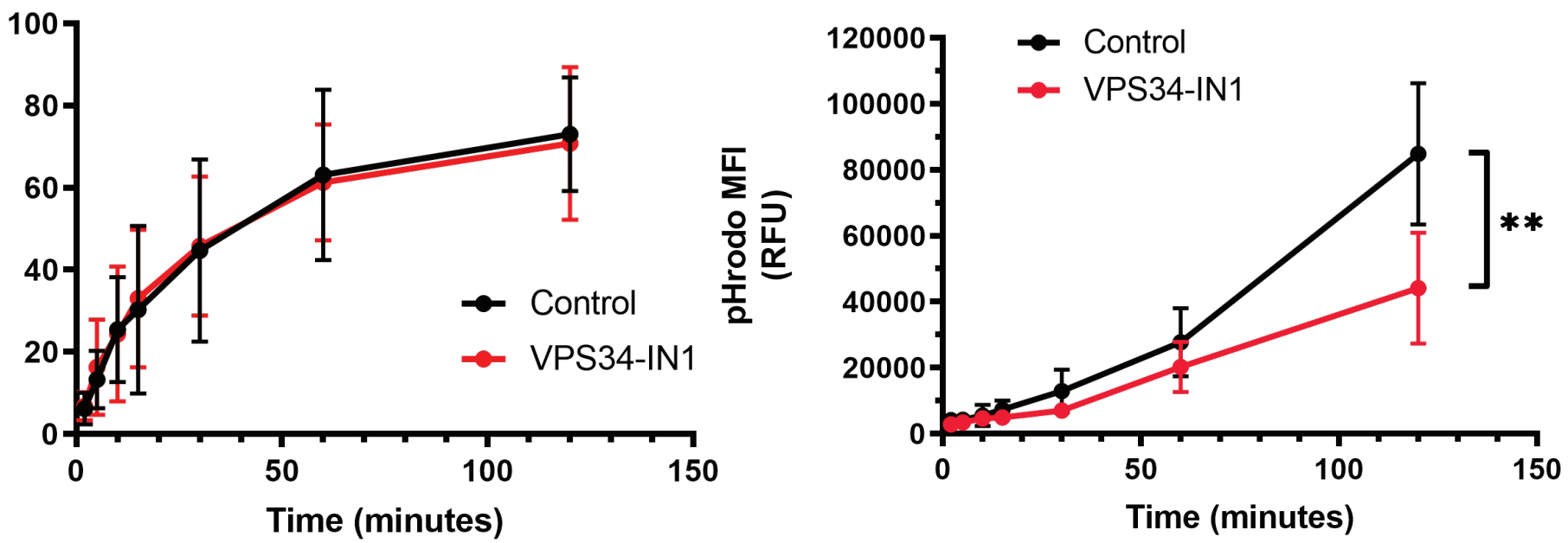


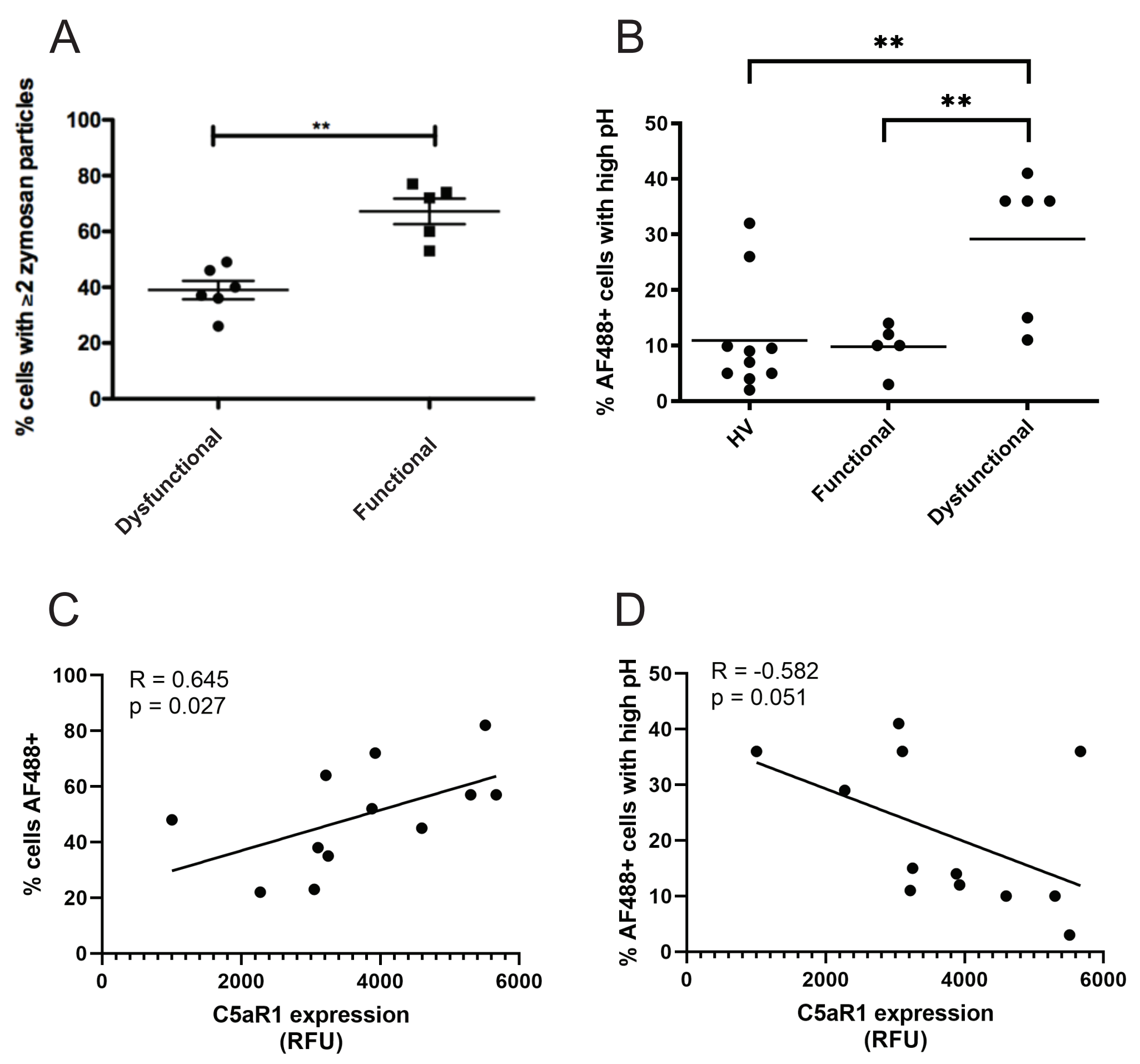

